\title{
Sensitivity analysis of cooling demand applied to a large office building
}

DOI:

10.1016/j.enbuild.2020.110703

\section{Document Version}

Accepted author manuscript

Link to publication record in Manchester Research Explorer

\section{Citation for published version (APA):}

Zeferina, V., Wood, R., Edwards, R., \& Tian, W. (2021). Sensitivity analysis of cooling demand applied to a large office building. Energy and Buildings, 235, [110703]. https://doi.org/10.1016/j.enbuild.2020.110703

\section{Published in:}

Energy and Buildings

\section{Citing this paper}

Please note that where the full-text provided on Manchester Research Explorer is the Author Accepted Manuscript or Proof version this may differ from the final Published version. If citing, it is advised that you check and use the publisher's definitive version.

\section{General rights}

Copyright and moral rights for the publications made accessible in the Research Explorer are retained by the authors and/or other copyright owners and it is a condition of accessing publications that users recognise and abide by the legal requirements associated with these rights.

\section{Takedown policy}

If you believe that this document breaches copyright please refer to the University of Manchester's Takedown Procedures [http://man.ac.uk/04Y6Bo] or contact uml.scholarlycommunications@manchester.ac.uk providing relevant details, so we can investigate your claim.

\section{OPEN ACCESS}




\section{Journal Pre-proofs}

Sensitivity analysis of cooling demand applied to a large office building

Vasco Zeferina, Ruth Wood

PII:

S0378-7788(20)33489-7

DOI: https://doi.org/10.1016/j.enbuild.2020.110703

Reference:

ENB 110703

To appear in:

Energy \& Buildings

Received Date:

13 June 2020

Revised Date:

16 November 2020

Accepted Date:

29 December 2020

Please cite this article as: V. Zeferina, R. Wood, Sensitivity analysis of cooling demand applied to a large office building, Energy \& Buildings (2020), doi: https://doi.org/10.1016/j.enbuild.2020.110703

This is a PDF file of an article that has undergone enhancements after acceptance, such as the addition of a cover page and metadata, and formatting for readability, but it is not yet the definitive version of record. This version will undergo additional copyediting, typesetting and review before it is published in its final form, but we are providing this version to give early visibility of the article. Please note that, during the production process, errors may be discovered which could affect the content, and all legal disclaimers that apply to the journal pertain.

(C) 2020 Published by Elsevier B.V. 
Full Title: Sensitivity analysis of cooling demand applied to a large office building

Corresponding Author: Vasco Zeferina,

Contact: Vasco.zeferina@gmail.com,

Mobile: +447751808038

ORCID: 0000-0001-5780-9909

Tyndall Manchester, School of Mechanical, Aerospace and Civil Engineering University of Manchester

Manchester, UK

Ruth Wood,

Tyndall Manchester, School of Mechanical, Aerospace and Civil Engineering University of Manchester

Manchester, UK

ORCID: 0000-0002-5992-1918

Rodger Edwards,

School of Mechanical, Aerospace and Civil Engineering

University of Manchester

Manchester, UK

ORCID: $\underline{0000-0002-4246-3949}$

Wei Tian - Tianjin University of Science and Technology, China

ORCID: 0000-0003-3447-2287

\section{ABSTRACT}

Previous dynamic building simulation studies have not often focused on analysing the sensitivity of peak loads to input parameters. However, these peak loads may have a critical impact on system design capacities and power network operation. This study aims to examine the sensitivity of cooling demand related results (total electricity demand, HVAC end-use and space cooling) in a large office building using two global sensitivity analysis methods: Morris elementary effect and Sobol indices. More specifically, this paper examines the implications of different type of climates to the uncertainty in these different cooling output results and the sensitivity of the different parameters for each result. 
Moreover, this paper investigates the difference between the effects of annual and peak analysis for cooling demand of office buildings, which can provide insight on cooling demand from the perspectives of total cooling energy and system capacity for building cooling systems, respectively.

This study has found that generally, the changes are more significant for peak demand than for annual demand. The coefficient of variation for the total peak demand is around $25 \%$ and $21 \%$ for total annual demand. This study identifies that the ventilation rate is the parameter that contributes the largest for the uncertainty in electricity demand of the HVAC end-use, between $50 \%$ to $70 \%$ of the change $\left(\mathrm{S}_{\mathrm{T}}\right)$, both for annual and peak demand. Regarding the effect on total electricity demand, ventilation rate is still one of the most critical factors, but equipment and lighting densities also become a significant contributor to the sensitivity of the total demand.

Key-words: EnergyPlus; Peak load; HVAC load; Space cooling load; Sensitivity analysis; Building simulation; Energy performance;

\section{Introduction}

Building performance simulation (BPS) is one of the most powerful analytical tools to assess the energy performance of buildings $[1,2]$. Within the building industry and building research area, these types of tools can help to address some of the unprecedented design challenges that are likely to exist in the years ahead (e.g.: adaptation to climate change impacts, crescent urbanisation and increasing complexity of systems operation). However, theutilisation and development of these models may present multiple challenges $[3,4]$, as this requires a detailed understanding of several complex sub-models and their interactions $[1,3,5]$. In addition, it requires detailed physical correctness of the model, thus detailed characterisation of the building's envelope and operation. Similarly, rational and sensible development of modelling approaches and definition of their outputs is required, to keep models targeted to the objectives of the simulation study $[1,5]$. Furthermore, the adaptation of buildings to the impacts of climate change is a main challenge in the design of buildings [1]. This will require detailed simulation to estimate how building energy performance changes with meteorological conditions and due to uncertainty of design conditions.

In recent years, it has been established that the predicted energy performance of buildings can significantly and systematically divergent from the real performance [6], this is referred to as the performance gap. De Wilde [4] emphasises that the performance gap literature is mainly focused on the differences between predicted energy use and measured in actual buildings. To bridge the gap, it 
is necessary to establish how, what and when measurements and estimations of energy demand should be compared. Also, it is necessary to understand that the energy performance models have limitations, and one should expect and accept differences between the model results and actual building performance. It is also important to use the correct modelling tools, and analysts should have the ability and knowledge to apply them appropriately [6]. In not doing so, the credibility of models, modellers and design teams is affected and the design solutions proposed by the industry to reduce energy consumptions, shave peak loads on buildings operations may be rejected.

Energy consumption of buildings has been reducing, driven by stricter guidelines and standards that follow more overarching initiatives to achieve international sustainability goals [1]. Some of these initiatives are the 20-20-20 targets in the EU or the net-zero emission target by 2050 in the UK. These have been particularly successful at reducing the heating demand of buildings through improvements in insulation and airtightness [7]. Stricter insulation and airtightness standards have led to more frequent episodes of overheating in naturally ventilated buildings during the warmest periods in the summer and during heatwaves over the last ten years [8]. These efforts to achieve high-performance buildings have been mainly focused on reducing energy demand. However, systematic and holistic design optimisation is needed to avoid unintended side effect from changes to building design standards $[1,5]$. This type of approach is necessary to evaluate the energy performance analysis of buildings in the future, as several types of uncertainties exist. On one hand, the uncertainty related to the rising temperatures due to the implications of climate change. On the other, the inherent uncertainty of the future technological scenarios assumptions on the building systems. Therefore, it is important to analyse and estimate how much additional space cooling requirements and inherent energy consumption for heating, ventilation and air conditioning (HVAC) systems are required, considering different scenarios and uncertainty on the set of design assumptions.

BPS is often applied to address design questions regarding optimisation and quantification of the annual energy demand of buildings, thermal comfort of occupants and sizing of HVAC components/systems [1]. More research has been done using BPS tools as computational capacity has been increasing. BPS tools can deliver results on a broad array of metrics, different periods and considering diversified assumptions. Most of the existing literature looking at the energy performance of buildings is focused on total annual energy demand and carbon emissions. It often analyses end- 
uses such as cooling and heating demand [9]. Some literature has studied overheating frequency [10], and only a minority has analysed the effects of cooling peak loads [11-13].

Cooling peak loads are in many cases crucial for building and HVAC system design, once they are critical to estimate HVAC system design capacity. Current standardised design procedures for HVAC capacity sizing are based on extreme weather conditions (design days) and safety factors, as professionals tend to minimise risks [14]. This lead to extreme oversizing of systems, and so to inefficient operation of the systems for most of the time, and much larger initial equipment costs. In addition, for power networks, the peak demands are often driven by the cooling requirement of buildings, in cooling dominated climates. However, in the literature analysed, building modelling approaches are often adapted to tackle other types of research questions, more focused on annual demands $[9,15]$. Thus, it is necessary to explore the implications on buildings' electricity peak demand due to changes on space cooling requirements.

For robust assessment of the peak electricity demand on buildings, simulations with an hourly temporal resolution are required, accounting for rapid building control responses, weather condition changes, and so for the transient response on building conditions. Dynamic building simulations are executed at hourly or sub-hourly resolution to capture the transient responses of building systems properties [16]. Dynamic building simulation tools employ mathematical models that account for physical principles of building systems. These type of tools can help to analyse different building design options and assumptions, but the modelling process can be extremely cumbersome.

Hensen et al. [1] conclude that computational simulation is a powerful analytical tool, but it is very difficult to ensure quality. Therefore, the building design community should pursue an understanding of the topic area. Uncertainty and sensitivity analysis techniques can enable further understanding of the parameters and factors that are most critical for the energy performance of buildings. This enables the accuracy of the models to be improved by updating model assumptions. On the other hand, it enables the dimensional reductions of models while preserving most of the variance. Thus, the number of model input iterations can be minimised, and still effectively analyse the possible range of building design choices.

Research studies using dynamic building simulation to assess the energy performance of buildings often use office building models (e.g.: [9]). This may be the case, as typically office buildings occupancy levels have more benchmark data available, significant energy intensity and present less 
discrepancy over the whole building stock data. Kavgic et al. [17] conclude that office buildings have similar occupant and operational use characteristics, and a clear distinction between occupied and unoccupied periods. The majority of office buildings have mechanical cooling and ventilation systems, due to high occupancy rates and significant density of internal heat gains. For example, in the UK, $70 \%$ of the office space area is estimated to have some sort of mechanical cooling [18]. Therefore, office buildings are a natural choice to analyse the implications of cooling demand for building electricity demand using archetype building models.

There is still limited understanding of how sensitive peak loads are on buildings, as much of the research focus has been in annual energy demand. Hourly analysis is required to capture the transient performance of the building system and to robustly estimate peak loads, which are critical for system design capacities and study the resilience of energy systems. Physical building models need to be executed at an hourly resolution to estimate annual peak loads. This requirement makes models more costly, but the detailed analysis of peak loads as discussed is crucial for many design decisions, especially in future climates and in buildings with cooling requirements, as discussed in further detail in the following paper section. The authors consider necessary to discuss in more detail previous sensitivity analysis on building energy simulation, to discuss the relevance of techniques utilised, different approaches assembled and the existing gap on analysing cooling demand, especially at peak loads.

Previous literature has not often focused on cooling demand for office buildings and their peak loads. However, these peak loads may have a critical impact on system design capacities and power network operation, as suggested by Wood et al. [19]. Therefore, this study aims to examine the sensitivity of cooling demand related results (total electricity demand, HVAC end-use and space cooling) in a large office building using two global sensitivity analysis methods: Morris elementary effect and Sobol indices. More specifically, this paper examines the implications of different type of climates to the uncertainty in these different cooling output results and the sensitivity of the different parameters for each result. Moreover, this paper would investigate the difference between the effects of annual and peak analysis for cooling demand of office buildings, which can provide insight on cooling demand from the perspectives of total cooling energy and system capacity for building cooling systems, respectively. This study would also be helpful to identify cooling design best practices for office buildings to guide energy engineers during the retrofit and development of new buildings. 
The paper will start by reviewing the existing literature on uncertainty and sensitivity of buildings energy performance (2) and discussing differences between sensitivity analysis methods. In the following section (3), the model assumptions, the modelling approach and the statistical methods utilised are described under the methodology section. In section 4, the results of the sensitivity analysis on peak and annual cooling demand of the archetype office building will be presented, analysed and discussed. Finally, in section 5 the conclusions are presented.

\section{Sensitivity analysis to assess building energy performance}

When a simulation model is utilised, uncertainties in the input parameters are propagated through the model and are echoed in the outputs. Sensitivity analysis (SA) is a statistical method used to quantify how the different inputs contribute to the variability of the outputs $[2,20]$. A related technique is the uncertainty analysis (UA), which studies the variability of the output results given the uncertainty of the input parameters and is often run in tandem with SA [2,20,21]. De Wilde [6] emphasises that it is necessary to include uncertainty in even the most accurate models. For this, It is necessary to start including probability density distributions instead of using deterministic parameters to execute building performance analysis (BPA).

SA can be divided into two main categories, local and global [20]. A local sensitivity analysis (LSA) evaluates the response of the model to one local parameter. Global sensitivity analysis (GSA) explores the response of the model to changes in all input parameters, which are varied simultaneously [20]. GSA provides more information about the effect of varying model inputs but demands more computational effort [20]. GSAs can be further subdivided into four categories [22]: regression, screening, variance-based and meta-models. The Morris elementary effect (EE) method is a screening method, which identify the effect of one input parameter at a time but makes the changes from different starting points [20]. This is considered to be a global method, even if it only changes one parameter value between consecutive simulations (one-at-a-time), which makes it a computationally efficient procedure. It is also a widely accepted technique used for different computational models. Regression methods compute statistic indicators of regression analysis on a sample of different model simulations results, to rank the importance of the input factors. Standardised regression coefficient (SRC) is a statistical index from the regression analysis that can be used to measure the linear relationship between outputs and inputs [23]. SRC methods are only suitable for linear models with uncorrelated inputs [22]. Variance-based methods decompose the 
deviation of the model output based on the uncertainty of input parameters [20]. These methods require significant computational effort, as a large number of sampling iterations are needed to guarantee stable and statistically robust results [22]. Sobol and Fourier amplitude sensitivity tests (FAST) are the most widely used variance-based GSA methods [20].

Variance-based GSA methods for complex models, such as dynamic building energy models, require large computational capacity [22]. Variance-based SA methods become unstable, biased and extremely costly with a large number of input parameters (more than 10) [23]. Therefore, during the initial building design, when more/larger design uncertainties exist, variance-based approaches may be inappropriate, as there are too many parameters for it to consider. At this stage, screening methods are recommended [23], as they identify the most significant parameters out of a larger set, with minimum computation cost. This approach can reduce the number of parameters to be analysed during the following more complex analysis. One approach often identified in the literature is to apply a multi-stage SA on building energy performance $[9,13,24]$. In an initial stage, a screening method such as the Morris EE $[9,24]$ or Lasso [13] is applied, which identifies the most relevant parameters. In the following stages, more detailed and complex GSA methods such as Sobol or FAST are applied to evaluate a reduced number of parameters.

In BPA, SA has been applied to investigate different types of modelling outputs: total energy demand [9], peak electricity loads [12], cooling and heating demand [9,25], carbon emissions[26] and overheat frequency [27]. For example, De Wilde et al. [27] has identified that lighting and equipment gains are the key factors for the annual electricity demand for cooling in office buildings. Sobol and FAST are some of the methods that have been used frequently to conduct SA in building energy models [9] and they are regarded as some of the most higly accurate sensitivity methods [22]. Even if they are computationally expensive, they enable the quantification of the interaction effect and single effect of different variables $[20,22,23]$. SRC is also often utilised (e.g. $[11,28])$; However, regression models have limitations when applied to non-linear systems such as buildings [22].

A smaller number of studies have looked at the sensitivity in peak cooling loads due to uncertainty on building model parameters [11-13]. Dominguez-Muñoz et al. [11] analyse the results of an office building model in Malaga, Spain, using a resistance-capacitance modelling method. Using an SRC for $\mathrm{SA}$, the main contributors for peak sensible space cooling are found to be thermal inertia parameters, thermal mass and internal convective coefficient, over a group of 20 parameters. Eisenhower et al. 
[12], for a building in Illinois, USA, use sensitivity decomposition indices based on analysis of variance (ANOVA) tests, and analyses the total sensitivity of total peak demand and annual consumption. Sun et al. [13] use the ANOVA method to calculate sensitivity indices on the chiller's and boiler's design peak load capacity.

Several studies have focused on analysing the uncertainty of peak cooling demand by considering a probable range of input parameters in dynamic building models [29-31]. For example, Huang et al. [32] conclude that the hourly cooling distribution is affected by two main factors, the weather conditions and the building type. Huang et al. [32] analysed the uncertainty of peak load on five different locations and for five different types of buildings. Also, Tian et al. [21] conclude that more effort is needed to rigorously quantify the uncertainty of input parameters for UA in BPA. In this review paper of UA in building energy assessment, Tian et al. [21] conclude that UA is ready to become a mainstream method in this research area and recommend that analysis should consider analysis based on different building types, weather conditions and building ages. However, these UA approaches are not able to inform and quantify the sensitivity of changes in design (envelope and system) input parameters.

The existing literature examining SA of energy demand in building energy models have shown the implications on annual demand, either for total energy, heating, cooling or carbon emissions. Few studies have focused explicitly on the sensitivity regarding cooling demand, and especially on electricity demand for HVAC end-use during peak periods. However, peak demand is critical to define design capacities of HVAC systems and to analyse energy systems operation limits. Moreover, current research using SA methods to analyse cooling peak demand is only executed for a single building, and a single climate [11-13]. However, some studies have identified that the sensitivity of the cooling output is high to changes in the weather parameters [33]. UA studies looking at peak cooling demand have also concluded that of the building types and climate are significant sources of uncertainty of cooling demand [32]. Therefore, this study will conduct a SA of a large set of parameters on peak and annual cooling demand of a large office building in a different type of climates, in order to improve current understanding on the topic of peak and annual cooling. A twostage SA is performed, as the initial screening can identify the main contributors for change in the outputs, with lower computational efforts. Morris EE method is the screening method utilised in this study, as it has been identified to be a very efficient procedure for this. On the second stage, a 
variance-based method can be executed with a reduced number of input parameters, providing more robust statistical information on the sensitivity of the building model. Sobol is used in this stage, as it is often regarded as one of the most accurate methods for building energy models.

\section{Methodology}

\section{Model Description: Building Conditions}

In research, in order to reduce the onerous task to model generic representative buildings, archetype models are often used. Archetype or reference building models are prepared to describe the main characteristics of a large sample of similar buildings that define a major class of buildings, such as the type of building use, building vintage and size [34]. The use of reference building models in the research methodology assures those modelling assumptions comply with relevant benchmark data. In addition, it makes research easily more replicable and easier to compare with similar research studies.

The US Department of Energy (DOE) collects important energy-related information through the Commercial Buildings Energy Consumption Survey. This project led to the development of national source data for the entire building stock [35]. Other institutions like the Chartered Institution of Building Services Engineers (CIBSE) and the American Society of Heating, Refrigerating and Airconditioning Engineers (ASHRAE) have collected and made available several other datasets that statistically describe the type of internal loads and schedules of building operations. These datasets yield detailed information for office buildings $[16,36]$. These data sources have been fundamental to develop archetype models.

The building energy model utilised in this research study is a large office model from the US DOE commercial reference buildings dataset [35], using EnergyPlus simulation software [37]. The DOE commercial reference buildings are a set of reference buildings developed by the US DOE, that are intended to represent the whole national building stock. Deru et al. [35] report in detail the development and reference characteristics of these models, including model definition and sources for the parameter values. The dataset also takes into consideration, for each type of building, three distinct construction vintages. Using the same base model assumptions for different locations in different countries may neglect the different design specificities of internal spaces, envelopes, and HVAC systems for different countries and regions. On the other hand, for an accurate study of the propagation of uncertainties in a model, there must exist standard base conditions to proceed on the 
analysis of the impacts of the parameters changes. In addition, one can argue that the uncertainty range study leads to design conditions that will differ significantly from initial design conditions for all locations. In this study, the building model base case was adapted from the large office reference model type, considering the most recent construct vintage (new 2004) and from the climate zone 3AMiami. Operation schedules for lighting, equipment and occupants in the model were adapted from Korlija et al. [38].

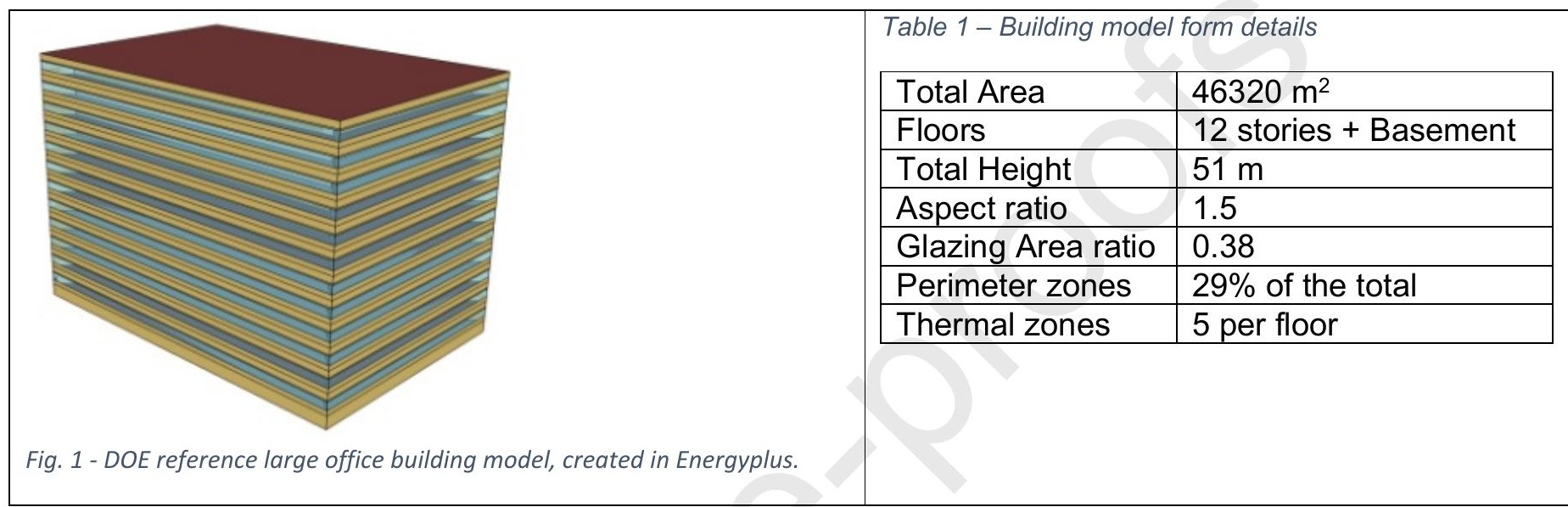

The input values presented as the standard DOE case is regarded as the base model case of this study. In Table 1, an overview is given of the building model form details. The total area of the building modelled is $46320 \mathrm{~m}^{2}$, in 12 equal stories for office spaces plus one basement storey. The space in each office floor is divided into four perimeter zones and a central core zone. The core zone represents $71 \%$ of the total floor area. The ratio between external building surfaces (external wall + roof) and floor space area is $35 \%$, and the ratio of glazed area per floorspace is $10.3 \%$. Two watercooled chillers are used as the cooling source and multizone variable air volume equipment is considered for space air distribution. The building model was created in EnergyPlus v8.1 [37] and statistical functions from sensitivity package in the $\mathrm{R}$ environment [39] were utilised to generate the building model input samples and calculate sensitivities indexes. JEplus [40] was used to manage the execution and for the collection and summary of the batch of simulation output results. 
Climate Information: C1-C6

a) Monthly Mean Dry Bulb Temperature

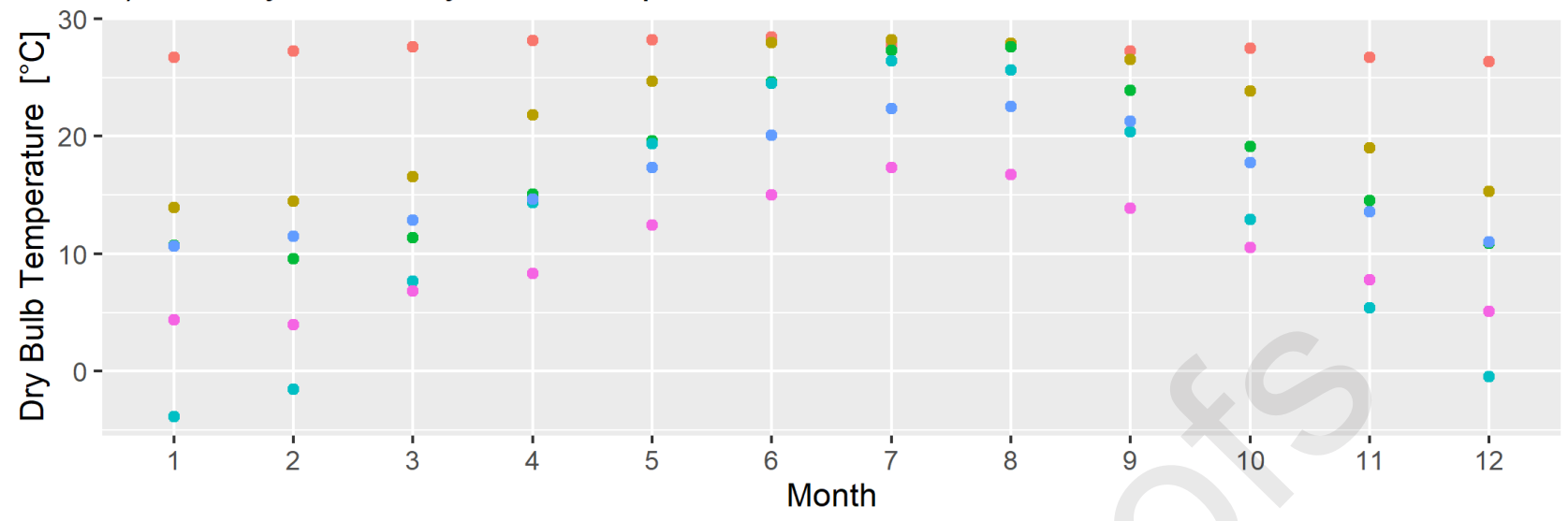

b) Global Hor. Rad.

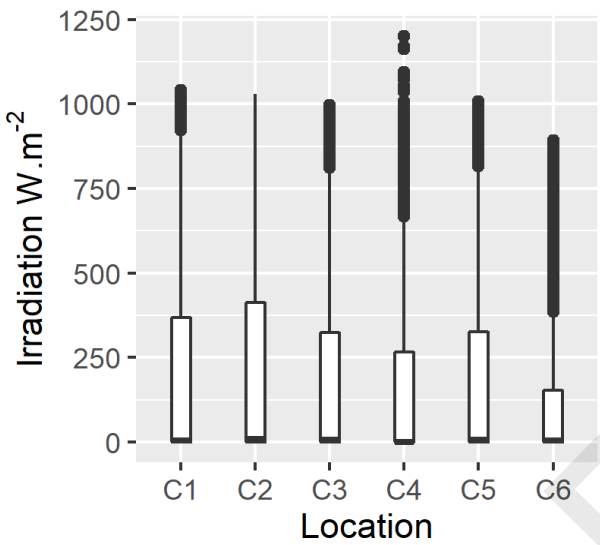

c) Relative Humidity

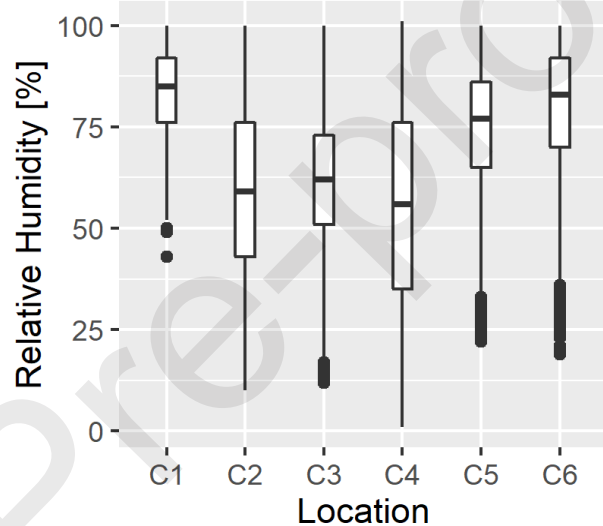

d) Dry Bulb Temperatı

\section{Fig. 2 - Climate variables annual distribution: a) Monthly mean DBT, and boxplot of annual values b)GHR, C)RH and d)DBT}

In this study, the sensitivity of the model was analysed considering different climate conditions, so six different locations were considered in the analysis, and these are: C1-Singapore, C2-Cairo, C3Athens, C4-Beijing, C5-Lisbon and C6-London. The weather files used to represent these climates are typical meteorological years (TMY), and were accessed from the EnergyPlus database [37]. TMY is an annual data set for a specific location, that holds hourly meteorological values that typify conditions over a longer period, normally 30 years [41]. These type of yearly weather files are synthesised by selecting individual months from different years of the period considered, which is referred to as the Sandia method. In Table 2, a summary overview of the climate data on these locations is presented.

The meteorological conditions in these locations are significantly different, as these aim to represent different types of climates. C1-Singapore weather is defined by a typical tropical humid climate, leading to almost constant requirement for space cooling. C2-Cairo is a hot desert climate, C3-Athens and C5-Lisbon present Mediterranean climates. C4-Beijing is a continental climate, and 
presents a large temperature amplitude between seasons, with a dry winter and a hot and humid summer. On the other hand, C6-London has a maritime humid climate, which drives much lower cooling requirements. These differences are expressed in the summary of the weather data presented in Table 2. Fig. 2 provides the summary statistics for several of the main weather variables: a) and d) dry bulb temperature (DBT), b) global horizontal radiation (GHR) and c) relative humidity (RH). Firstly, the number of cooling degree days $(C D D)$ between all these locations varies between a minimum of 32 in C6-London and 3454 in C1-Singapore. The maximum annual dry-bulb temperature is the highest for $\mathrm{C} 2-\mathrm{Cairo}$, with $43^{\circ} \mathrm{C}$, and the lowest being for C6-London with a value of $31.8^{\circ} \mathrm{C}$.

Table 2 - Summary of weather files used

\begin{tabular}{|l|c|c|c|c|c|c|}
\hline & $\begin{array}{c}\mathrm{C} 1 \\
\text { Singapore }\end{array}$ & $\begin{array}{c}\mathrm{C} 2 \\
\text { Cairo }\end{array}$ & $\begin{array}{c}\mathrm{C} 3 \\
\text { Athens }\end{array}$ & $\begin{array}{c}\mathrm{C} 4 \\
\text { Beijing }\end{array}$ & $\begin{array}{c}\mathrm{C} 5 \\
\text { Lisbon }\end{array}$ & $\begin{array}{c}\mathrm{C} 6 \\
\text { London }\end{array}$ \\
\hline $\begin{array}{l}\text { Maximum DBT } \\
\mathrm{CDD} \text { (base }\end{array}$ & $33.8^{\circ} \mathrm{C}$ & $43^{\circ} \mathrm{C}$ & $37.2^{\circ} \mathrm{C}$ & $37.2^{\circ} \mathrm{C}$ & $36^{\circ} \mathrm{C}$ & $31.3^{\circ} \mathrm{C}$ \\
\hline $18^{\circ} \mathrm{C}$ ) & 1747 & 1075 & 836 & 474 & 32 \\
\hline
\end{tabular}

\section{Model Input Uncertainty: Data Range / Parameters}

Table 3 presents the list of input parameters on the input space of the building model, specifying their standard base value and the range limit of values considered on the SA conducted in this study. The selection of the input parameters for this study are based in the parameters that have been previously identified in the literature to have the larger implications for the energy demand of buildings $[9,22]$, and preliminary studies conducted $[24,33]$. The standard base value of each parameter is defined based on the input conditions of the large office reference model case chosen as the base case. For more details, refer to [35] and supplementary data section. Whenever the impacts of a particular parameter are not to be explored in the SA iteration approach, this parameter in the building model is assumed as the standard base case value. The quantification of uncertainty on the probabilistic distribution for input parameters is the most difficult aspect on UA [13,21]. A number of studies from the high-performance building lab at Geogia Tech University $[13,14,32,42-45]$ has been looking at the quantification and understanding of uncertainty analysis for building performance simulation. In this study, the archetype model is representing several vintages and locations, and so different benchmark data are concatenated. Uniform distributions are commonly used to represent different possible design strategies [21]. In this study, the 14 design input parameters are considered as continuous variables and the inputs ranges are assumed to be a uniform distribution. The limits of 
their ranges are based on previous publications [9], the range of existing parameters on the reference model dataset [35] and on benchmark values given in standards and guidelines $[36,46,47]$.

\section{a) Lighting}

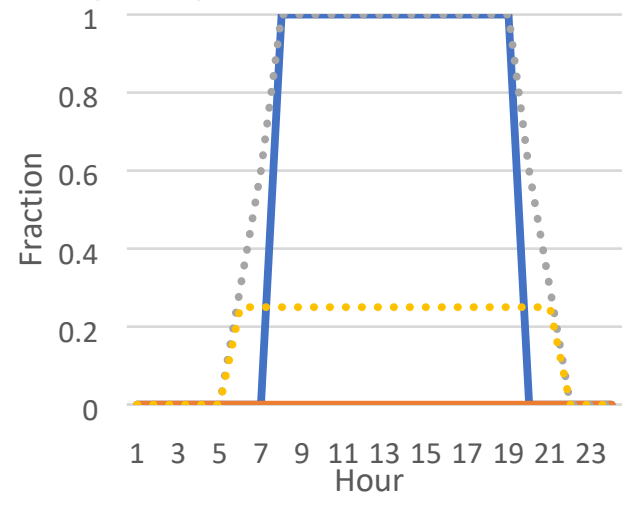

Weekday-Normal
Weekend-Normal
$\ldots .$. Weekday-Max
$\ldots .$. Weekend-Max
b)Equipment

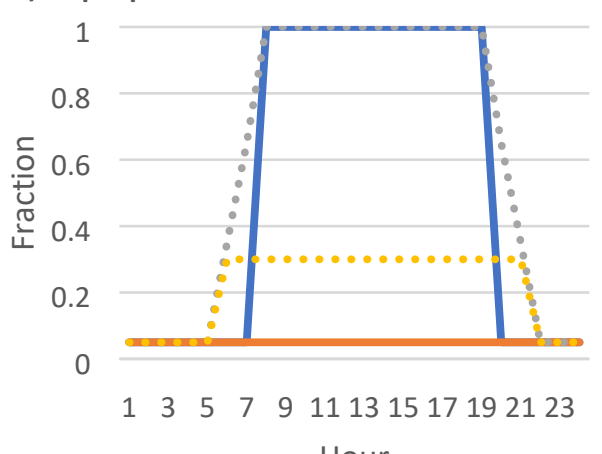

Hour

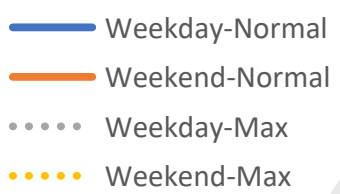

c)People

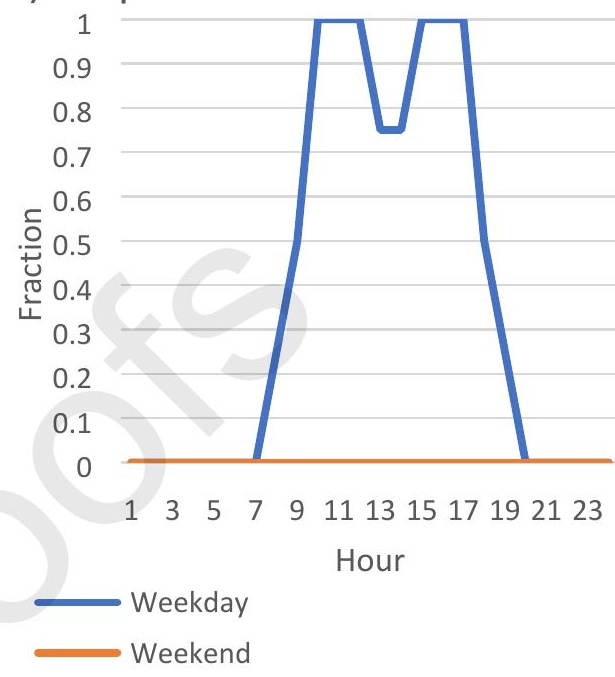

Fig. 3 - Schedules used on simulations assumptions, a) lighting, b) equipment and c) people

For the parameter P14, the number of effective annual hours of operation for equipment and lighting were controlled. Thus, the range values were set from a standard base of 3132 for lighting and 3602 for equipment to a maximum of 4007 and 4285, respectively. This was achieved stretching the operational index of schedules during weekend hours (6 am-9 pm) and on the margins of the standard workdays (6 am - 7 am and 8 pm - 9 pm). An illustration of the changes in the schedules is shown in Fig. 3. The choice to have large amplitudes of input parameters ranges, and uniform distribution of these ranges, is made as this study intends to evaluate design parameter options. Therefore, the methodology is not focused on comparing the plausibility of each value within the range. Nevertheless, the input ranges are chosen based on limit values that are considered possible to occur as design parameters and have been reported in previous literature. To determine the limit range of ventilation (P10) and infiltration (P11), larger amplitudes were considered as the rates can be fine controlled and assumptions can be substantially different based on the operation of the space, for example, due to the indoor air quality (IAQ) requirements needed or the number of people.

Table 3 -Input Parameters used on sensitivity analysis

\begin{tabular}{|c|l|c|c|c|c|}
\hline \multicolumn{1}{|c|}{ Description } & Unit & $\begin{array}{c}\text { Lower } \\
\text { Limit }\end{array}$ & $\begin{array}{c}\text { Upper } \\
\text { Limit }\end{array}$ & Std DOE \\
\hline P01 & $\begin{array}{l}\text { Conductivity of the concrete } \\
\text { layer on the external wall }\end{array}$ & W. $\mathrm{m}^{-1} \cdot \mathrm{K}^{-1}$ & 0.1 & 2 & 1.311 \\
\hline P02 & Roof Conductivity & W. $\mathrm{m}^{-1} \cdot \mathrm{K}^{-1}$ & 0.005 & 0.08 & 0.049 \\
\hline P03 & $\begin{array}{l}\text { Solar heat gain coefficient } \\
\text { (SHGC) }\end{array}$ & - & 0.075 & 0.5 & 0.25 \\
\hline
\end{tabular}




\begin{tabular}{|c|l|c|c|c|c|}
\hline P04 & Window U-value & W.m $\mathrm{m}^{-2} \cdot \mathrm{K}^{-1}$ & 1 & 7 & 6.92716 \\
\hline P05 & Lighting & $\mathrm{W} \cdot \mathrm{m}^{-2}$ & 5 & 20 & 10.76 \\
\hline P06 & Equipment & $\mathrm{W} \cdot \mathrm{m}^{-2}$ & 6 & 22 & 10.76 \\
\hline P07 & Floor space per person & $\mathrm{m}^{2} \cdot \mathrm{p}^{-1}$ & 5 & 20 & 18.58 \\
\hline P08 & Ambient temperature set-point & ${ }^{\circ} \mathrm{C}$ & 21 & 26 & 24 \\
\hline P09 & Cooling water set-point & ${ }^{\circ} \mathrm{C}$ & 5.5 & 8 & 6.7 \\
\hline P10 & Ventilation & $\mathrm{m}^{3} \cdot \mathrm{s}^{-1} \cdot \mathrm{m}^{-2}$ & 0.0002 & 0.005 & 0.000625 \\
\hline P11 & Infiltration of & $\mathrm{m}^{3} \cdot \mathrm{s}^{-1} \cdot \mathrm{m}^{-2}$ & 0.0001 & 0.003 & 0.000302 \\
\hline P12 & $\begin{array}{l}\text { Reference coefficient } \\
\text { performance (COP) }\end{array}$ & - & 4 & 7 & 5.5 \\
\hline P13 & Minimum chiller's unload ratio & - & 0.1 & 0.3 & 0.2 \\
\hline P14 & Schedule stretch & - & 0 & 1 & 0 \\
\hline
\end{tabular}

P05- $06-07-10$ - per floor space area

$\mathrm{P} 11$ - per external envelope surface area

P13 - it is where the chiller capacity can no longer be reduced by unloading

Modelling Framework

The SA approach of this study is conducted in two stages. Six climates are considered, and the sensitivity of 14 input model parameters is analysed, for four different output variables at both peak and annual demand span; therefore eight output results are analysed. The first sensitivity stage applies a screening method, the Morris EE, considering all the 14 input parameters and over the six climates. This stage is aimed to identify the parameters that contribute the most for each output results. On the second sensitivity stage, a more detailed sensitivity method is applied, the Sobol indices, which requires more computational resources, but enables more detailed and quantifiable measurement of sensitivities. The coefficient of variation was calculated to measure the dispersion of the distribution of the outputs. To reduce the number of samples to be simulated in this stage, eight parameters from the initial stage are kept fix and only the uncertainty of six input parameters is studied. The choice of these six parameters is based on the sensitivity results achieved in the first stage. The quantities of interest of the SA in this study was the annual demand and peak demand for total electricity, HVAC end-use (pumps, fans, chiller and heat rejection), non-HVAC demand, and space cooling demand (SPC). A detailed description of these variables on EnergyPlus model outputs is given in the supplementary section A6.EneryPlus output variables.

\section{Coefficient of Variation}

The coefficient of variation $\left(c_{v}\right)$ is a measure of the variability of a population in relation to the mean of this population and can be written as Eq.(1). It is the ratio between the standard deviation of the population $(\sigma)$ to the mean of the population $(\mu)$. In this study, the coefficient of variation was calculated for all output results of each location, for both Morris and Sobol methods. 


$$
c_{v}=\frac{\sigma}{\mu}
$$

\section{Morris EE method}

The Morris EE method is a screening method, a simple but efficient way to evaluate the contribution of the main input parameters, among the many that can exist in a model [20], to changes in the output results, in this case: electricity demand end-uses and SPC at annual and peak level. This method determines two quantitative sensitivity measures, the mean $\left(\mu^{*}\right)$ and standard deviation $(\sigma)$. The mean $\mu^{*}$ measures the overall influence of the input factor analysed on the model output. The standard deviation $\sigma$ assesses the effect of factors due to the interaction with the other parameters. An extended description of the method is done by Saltelli et al. [20]. The sampling of the method consider $k$ independent inputs $\left(X_{i}\right)$, each parameter varies across $p$ selected levels within the input range, which creates equidistant spaces between input points. The method produces multiple trajectories $(r)$, with $(k+1)$ samples, where two consecutive samples only differ in one input parameter value, which is changed by relative fix distance in that coordinate $\left(X_{i}\right), \Delta$. The equations of elementary effect (EE), the mean $\left(\mu^{*}\right)$, and standard deviation $(\sigma)$ can be written as Eq.(2), Eq.(3), Eq.(4), respectively.

$$
\begin{gathered}
E E_{i, j}\left(x_{l}\right)=\frac{\left[y\left(x_{l+1}\right)-\mathrm{y}\left(x_{l}\right)\right]}{\Delta} \\
\mu_{i}^{*}=\frac{1}{r} \sum_{j=1}^{r}\left|E E_{i, j}\right| \\
\sigma_{i}^{2}=\frac{1}{r-1} \sum_{j=1}^{r}\left(E E_{i, j}-\mu\right)^{2}
\end{gathered}
$$

Where,

$$
\begin{array}{cc}
\mu_{i}{ }^{*} & \text { Mean, sensitivity measure } \\
\sigma_{i} & \text { Standard deviation, sensitivity measure } \\
E E_{i}^{j} & \text { Elementary effect relative to factor } i \text { along trajectory } j \\
r & \text { Total number of trajectories } \\
j & \text { Current trajectory } \\
i & \text { Parameter analysed } \\
\Delta & \text { Sampling distance interval }
\end{array}
$$

In the Morris EE stage of this study, a total of 14 input parameters are to be screened, considering that each input parameter range is varied across eight equidistant selected levels $(p)$ and considering a total number of 90 trajectories $(r)$. This number of trajectories is considered a large enough number 
of trajectories for the number of parameters and levels selected [48]. Each trajectory includes 15 samples $(14+1)$ configurations and thereby creates a total number of 1200 samples. The method was applied considering each of the six climates, consequentially generating a total number of 7200 simulations. The sensitivity metrics, $\mu^{*}$ and $\sigma$ are calculated for each one of the output metrics considered. The importance of input parameters are ranked based on the $\mu^{*}$, and an assessment of the influence on each output metric is done and contrasted between the different climates.

\section{Sobol indices}

The second stage of the sensitivity approach of this study applies a more complex variance-based method, the Sobol method. Sobol is considered to be one of the most efficient methods to quantify the variance of the output and decompose it according to the uncertainty of input factors [20]. At this stage, the approach considers uncertainty in six input parameters, three for internal heat gains: lighting - P05, equipment - P06, and people - P07, ambient set point - P08, ventilation rate - P10 and cooling reference COP - P12. The Sobol method considered used two random samples with 2500 iterations of the input parameters using random sampling techniques. Thereafter, six more sample matrixes $\left(C_{i}\right)$ were generated, based on the replacement of values in sample $A$ by the correspondent parameter values on sample $B$. This makes a total number of 20000 iterations of the building model condition, as there are two base sample iterations $(A$ and $B)$, and six more transformed samples $(C)$.

Fig A.5-1 and Fig A.5-2 show the convergence of Sobol indices, both on Peak and Annual total electricity demand for all parameters, with the sample size, which indicates the stability of the results presented.

Variance effect indices are computed giving the full impact input sample iterations, measuring the first-order $\left(S_{i}\right)$ and total-effect indices $\left(S_{T}\right)$ of the input model parameters. $S_{i}$ is the measure of the main effect of the parameter, indicating how much the output variance could be reduced if the parameter $i$ could be fixed. $S_{T}$ is the total-effect Sobol index, and it is the addition of the parameter's main effect and the interaction effect with other parameters. The main effect $\left(S_{i}\right)$ and the total effects $\left(S_{T}\right)$ can be computed as Eq.(5) and Eq.(6) from Saltelli et al. [20].

$$
\begin{gathered}
S_{i}=\frac{V\left[E\left(Y \mid X_{i}\right)\right]}{V(Y)} \\
S_{T}=1-\frac{V\left[E\left(Y \mid X_{\sim i}\right)\right]}{V(Y)}
\end{gathered}
$$


where,

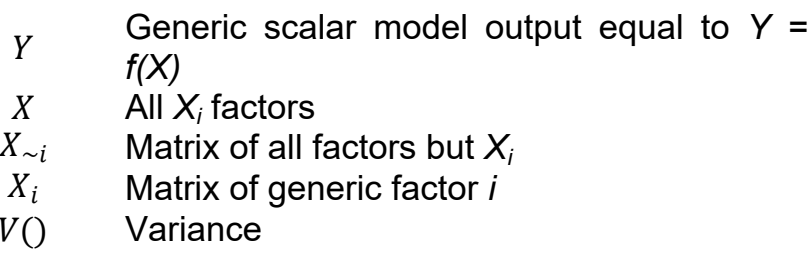

In this study, the Martinez estimators [49] are used, which implements a Monte Carlo sampling based procedure to estimate the Sobol indices. This method is found as a function in R sensitivity package [39], which offers several global sensitivity methods.

\section{Results and discussion}

\section{Base case and mean results of simulation samples}

Looking at the end-use electricity consumption, in Fig. 4, for the different locations, it is clear that changes between locations are mainly due to changes in chiller end-use. For annual demand, in Fig. 4 (a), the total demand for C1-Singapore is $235 \mathrm{kWh} \cdot \mathrm{m}^{-2} \cdot \mathrm{yr}^{-1}$, and $53 \%$ of this is for HVAC end-use (124 $\left.\mathrm{kWh} \cdot \mathrm{m}^{-2} \cdot \mathrm{yr} \mathrm{r}^{-1}\right)$. On the other hand, in C6 London, the total annual demand is $137 \mathrm{kWh} \cdot \mathrm{m}^{-2} \cdot \mathrm{yr}^{-1}$, which $19 \%$ are for HVAC demand (26 kWh. $\left.\mathrm{m}^{-2} \cdot \mathrm{yr}^{-1}\right)$. For peak demand, in Fig. 4 (b), C4-Beijing is the location that presents the largest total peak load of $65.7 \mathrm{~W} \cdot \mathrm{m}^{-2}$. Chiller load is $25.8 \mathrm{~W} \cdot \mathrm{m}^{-2}(70 \%$ of HVAC) and fans end-use is $5.9 \mathrm{~W} \cdot \mathrm{m}^{-2}$ (16\% HVAC). Interestingly, fans end-use loads can be significantly lower for other locations, during peak periods, as low as $2.5 \mathrm{~W} \cdot \mathrm{m}^{-2}$ (C3) and $1.8 \mathrm{~W} \cdot \mathrm{m}^{-2}$ (C6), respectively $9 \%$ and $10 \%$ of HVAC Load. The share of HVAC end-use (Chiller + Fans + Heat Rejection + Pumps) on the total peak load is the largest for C4-Beijing (56\%) and the lowest for C6London (37\%).

What is interesting about the share of the HVAC end-use on total load, is that it is significantly larger for peak demand than it is for annual demand. C1-Singapore is an exception, as it shows similar levels of HVAC share on the total for annual (53\%) and peak demand (55\%). On the other hand, C4-Beijing goes from $28 \%$ for annual demand to $56 \%$ on the peak. Interestingly, results for space cooling load (SPC) show different pattern between locations than for HVAC demand. The differences shown between patterns in SPC and HVAC results may be explained by the difference in the efficiency of the operation of systems. Looking at Table A.4-3 and Table A.4-4, it can be seen that 
the annual energy efficiency ratio for $\mathrm{C} 1$ is much lower than for other locations. A reason for that is the reduced availability for free-cooling in such a climate. This is confirmed by a larger amount of chiller load in this site.

The differences in demand patterns between annual and peak between locations can be explained in part by the clear seasonality of weather experienced in most of the locations analysed in this study. Except for C1-Singapore, presenting a tropical climate, which does not present clear-cut seasons and the weather is humid and warm all year round. Therefore, it is expectable that annual energy consumption for HVAC-end use for such a location is significantly larger than for the other locations analysed in this study. Therefore, changes in total annual demand for HVAC are also affected differently in this location than for the remaining. One objective of this study was to identify if the sensitivity of the building model outputs is larger for peak or annual demand. Stating the differences between locations on the initial base-case is important for a discussion of the sensitivity results in following sub-sections.

a) Annual

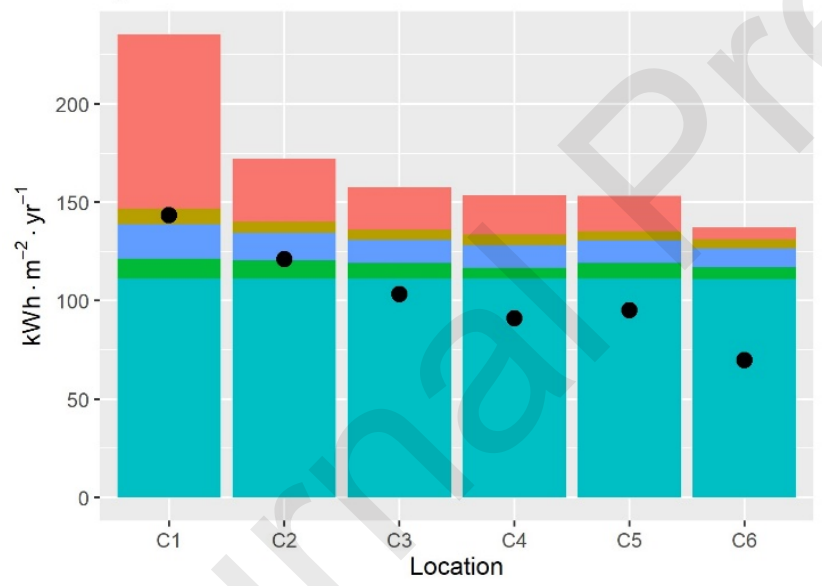

b) Peak

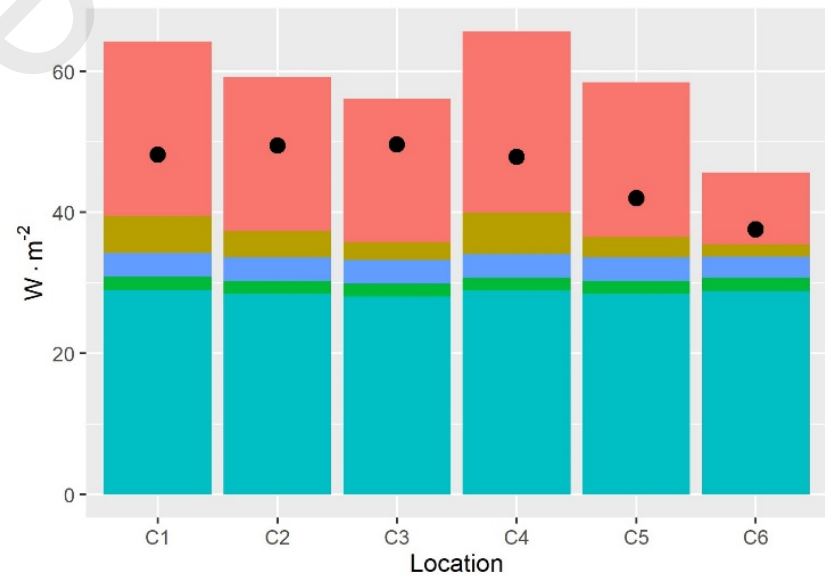

Fig. 4 - Mean electricity energy consumption and space cooling using Morris EE method sample, for annual (a) and peak (b) , by end-Use 
Range of simulation results of building thermal performance in six cities
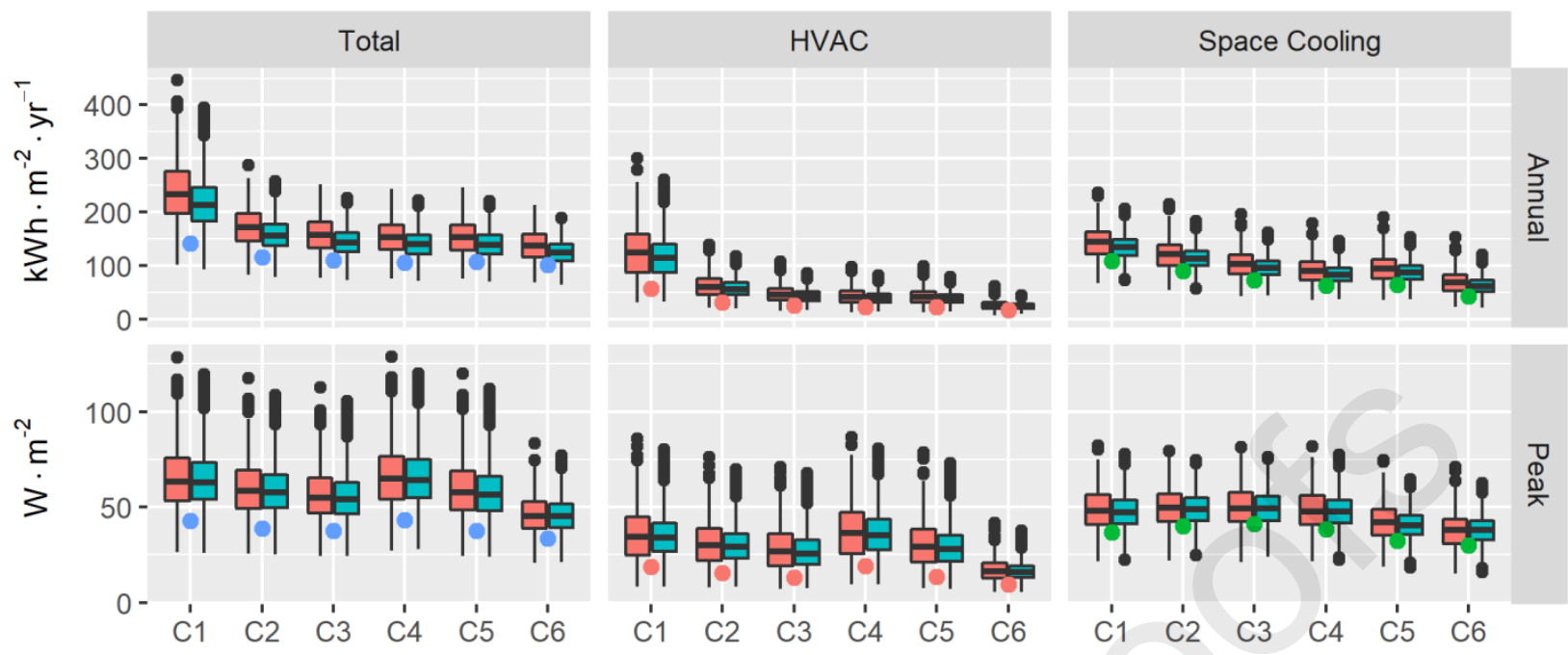

Base Case

\section{Location}

Fig. 5 - Boxplot diagram of results for Morris EE and Sobol methods, comparing to base case simulation results

The analyse of the distribution of the results for each output variable analysed within the different locations, in Fig. 5, clearly show that the pattern of changes in the whole sample of results is similar across the different locations. In addition, the differences between locations are different according to annual or peak demand, and between different variables. From the results presented in Fig. 5 , it is also clear that base case results are on the bottom end quantile of sample results, among the different outputs for both annual and peak demand. It is also clear that Morris sample results range is slightly wider than Sobol results. These discrepancies could be attributed to the fact that Sobol sample is only iterating a selected batch of parameters (6) from the input space used on Morris EE method (14), considering the same range limits.

The position of base case results, shown in Fig. 5, within the whole range of the sample results are likely to be related to the selection of the input parameters ranges for the building model inputs. The main driver may be the selection of the base value within the limits of the input parameter range. In Fig. 6 , it is possible to identify that most of the base parameter values are within the middle quantiles of the chosen parameter range. However, the base value of some parameters is clearly on the bottom or top end of its intervals. P10, ventilation, is one of these parameters, and P10 is the parameter with the largest individual contribution to changes in most of the output variables analysed (presented and discussed in further detail in following subsection 0 and 0 ). Therefore, having its base value at the 
bottom end of the input range interval leads to the overall results within the sample to being offsetted from the base case result.

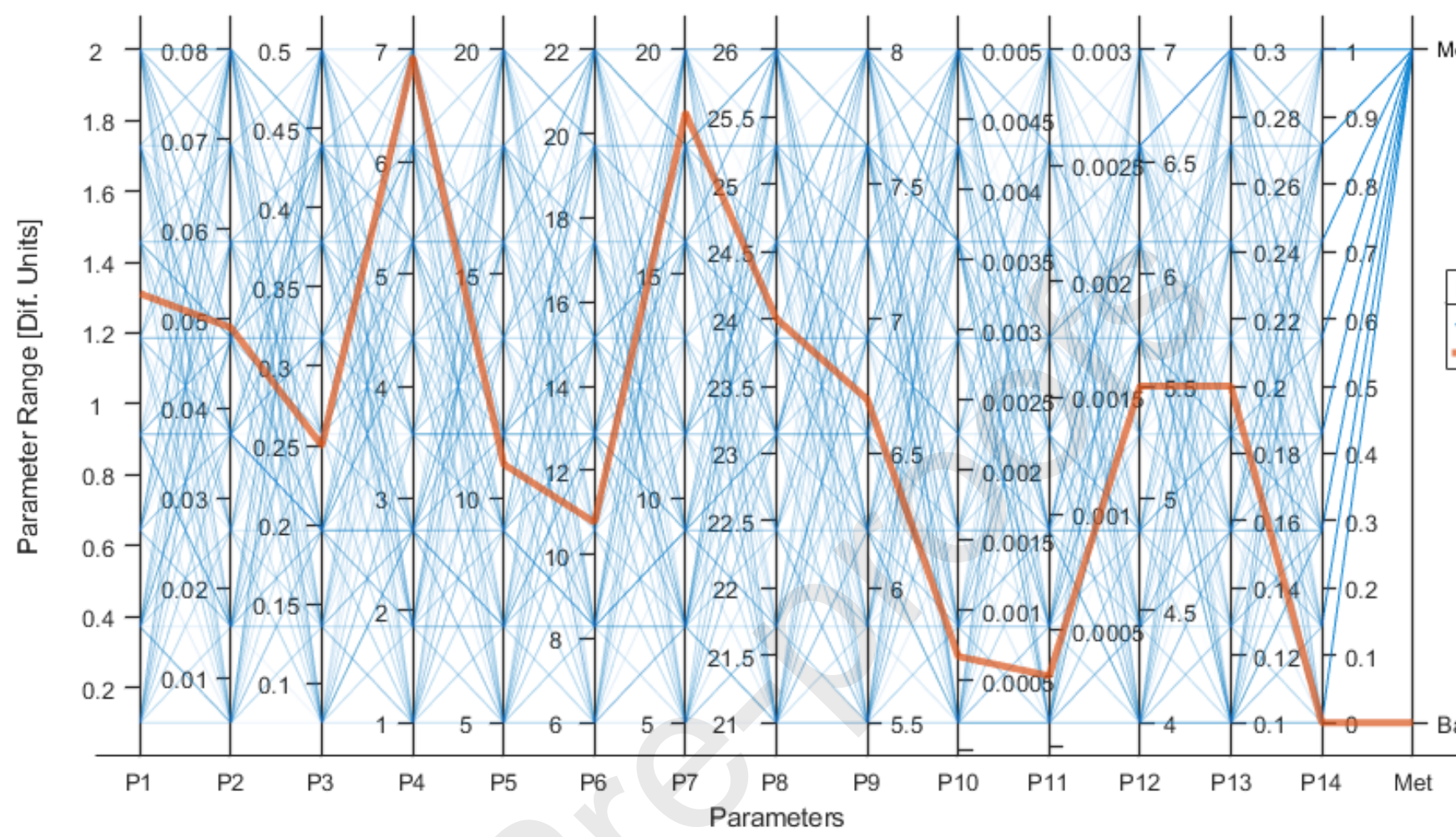

Fig. 6 - Position of base case parameters within each input parameter space range

Table 4-Coefficient of variation ( $c_{v}$ ) of Morris Method sample

\begin{tabular}{|c|c|c|c|c|c|c|c|c|c|c|c|c|}
\hline & \multicolumn{6}{|c|}{ Annual } & \multicolumn{6}{|c|}{ Peak } \\
\hline & C1 & C2 & $\mathrm{C} 3$ & C4 & $\mathrm{C} 5$ & C6 & C1 & $\mathrm{C} 2$ & $\mathrm{C} 3$ & C4 & $\mathrm{C} 5$ & $\mathrm{C} 6$ \\
\hline Total & $\begin{array}{l}24.3 \\
\%\end{array}$ & $\begin{array}{l}21.1 \\
\%\end{array}$ & $\begin{array}{l}20.9 \\
\%\end{array}$ & $\begin{array}{l}21.0 \\
\%\end{array}$ & $\begin{array}{l}21.0 \\
\%\end{array}$ & $\begin{array}{l}21.4 \\
\%\end{array}$ & $\begin{array}{l}25.7 \\
\%\end{array}$ & $\begin{array}{l}24.5 \\
\%\end{array}$ & $\begin{array}{l}24.5 \\
\%\end{array}$ & $\begin{array}{l}25.6 \\
\%\end{array}$ & $\begin{array}{l}25.7 \\
\%\end{array}$ & $\begin{array}{l}21.8 \\
\%\end{array}$ \\
\hline$\frac{\text { HVA }}{\underline{C}}$ & $\begin{array}{l}38.0 \\
\%\end{array}$ & $\begin{array}{l}33.3 \\
\%\end{array}$ & $\begin{array}{l}31.4 \\
\%\end{array}$ & $\begin{array}{l}31.9 \\
\%\end{array}$ & $\begin{array}{l}31.6 \\
\%\end{array}$ & $\begin{array}{l}28.9 \\
\%\end{array}$ & $\begin{array}{l}39.7 \\
\%\end{array}$ & $\begin{array}{l}38.5 \\
\%\end{array}$ & $\begin{array}{l}40.8 \\
\%\end{array}$ & $\begin{array}{l}39.1 \\
\%\end{array}$ & $\begin{array}{l}41.2 \\
\%\end{array}$ & $\begin{array}{l}33.8 \\
\%\end{array}$ \\
\hline$\underline{\text { SPC }}$ & $\begin{array}{l}19.4 \\
\%\end{array}$ & $\begin{array}{l}21.9 \\
\%\end{array}$ & $\begin{array}{l}24.0 \\
\%\end{array}$ & $\begin{array}{l}25.4 \\
\% \\
\end{array}$ & $\begin{array}{l}26.4 \\
\%\end{array}$ & $\begin{array}{l}30.4 \\
\% \\
\end{array}$ & $\begin{array}{l}22.3 \\
\%\end{array}$ & $\begin{array}{l}20.1 \\
\% \\
\end{array}$ & $\begin{array}{l}21.2 \\
\%\end{array}$ & $\begin{array}{l}21.7 \\
\%\end{array}$ & $\begin{array}{l}22.0 \\
\% \\
\end{array}$ & $\begin{array}{l}23.5 \\
\%\end{array}$ \\
\hline
\end{tabular}

To compare and quantify the difference between the changes on different output metrics (variables analysed) over the sample of simulations, the coefficient of variation $\left(c_{v}\right)$ of the different output metrics is analysed. Coefficient of variations were calculated for each location, output metric and time resolution, which are presented in Table 4. Closer inspection of the table shows that variation in electricity demand over peak is larger than for annual demand. For example, the coefficient of variation of the total electricity is close to $25.6 \%$ for peak and $21 \%$ for annual demand. However, for C1-Singapore and C6-London the coefficients of variation for total peak and annual demand are much closer to each other than for the other locations (C1- $25.7 \%$ vs $24.3 \%$ and C6- $21.8 \%$ vs $21.4 \%$ ). 
Turning now to the analysis of the coefficient of variation of the different HVAC demand, it is possible to see that variation can be around $40 \%$ for peak and $32 \%$ for annual demand (in C2-3-4-5). Interestingly, the Fans end-use shows the largest coefficient of variation for peak demand, reaching up to $80 \%$ (C5), when it is $35 \%$ for annual demand. In the supplementary material of this paper, more results from the variance of results between the different climates, periods and output variables are given.

For space cooling demand, the impacts over annual demand are larger than for peak demand, especially for C6-London and in less extent for C1-Singapore. For space cooling output variable, the variance of the results for peak demand is similar among all locations (going from $20 \%-\mathrm{C} 2$ to $23.5 \%$ C6). For the annual demand case, the differences between locations are more significant, from $19 \%$ in $\mathrm{C} 1$ to $30.4 \%$ in $\mathrm{C} 6$. This clearly shows that the location due to the respective climate conditions have different implications for the HVAC performance and respective space cooling requirements. 


\section{Sensitivity results from the Morris EE method}
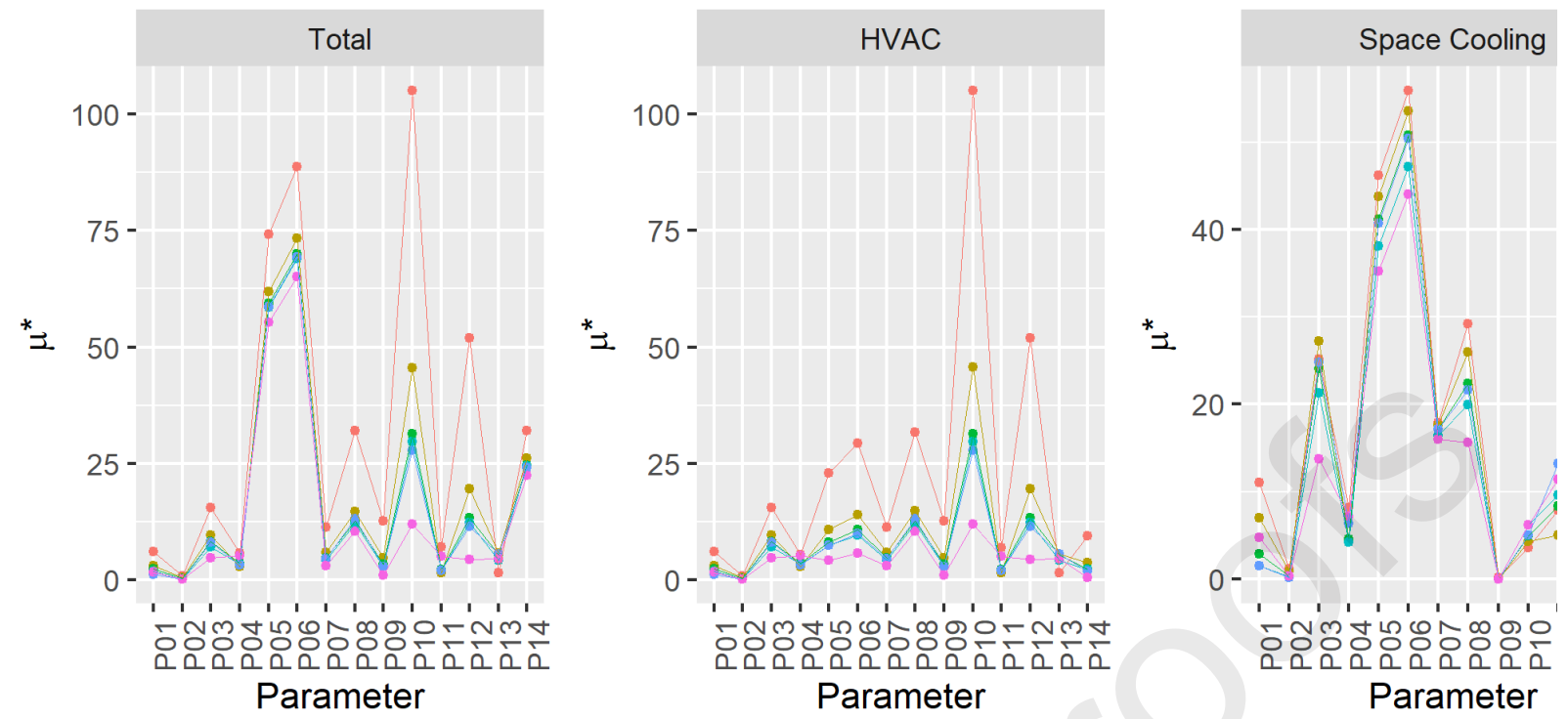

Fig. 7 - Morris EE $\mu^{*}$ indices for each input parameter relative to annual demand output results
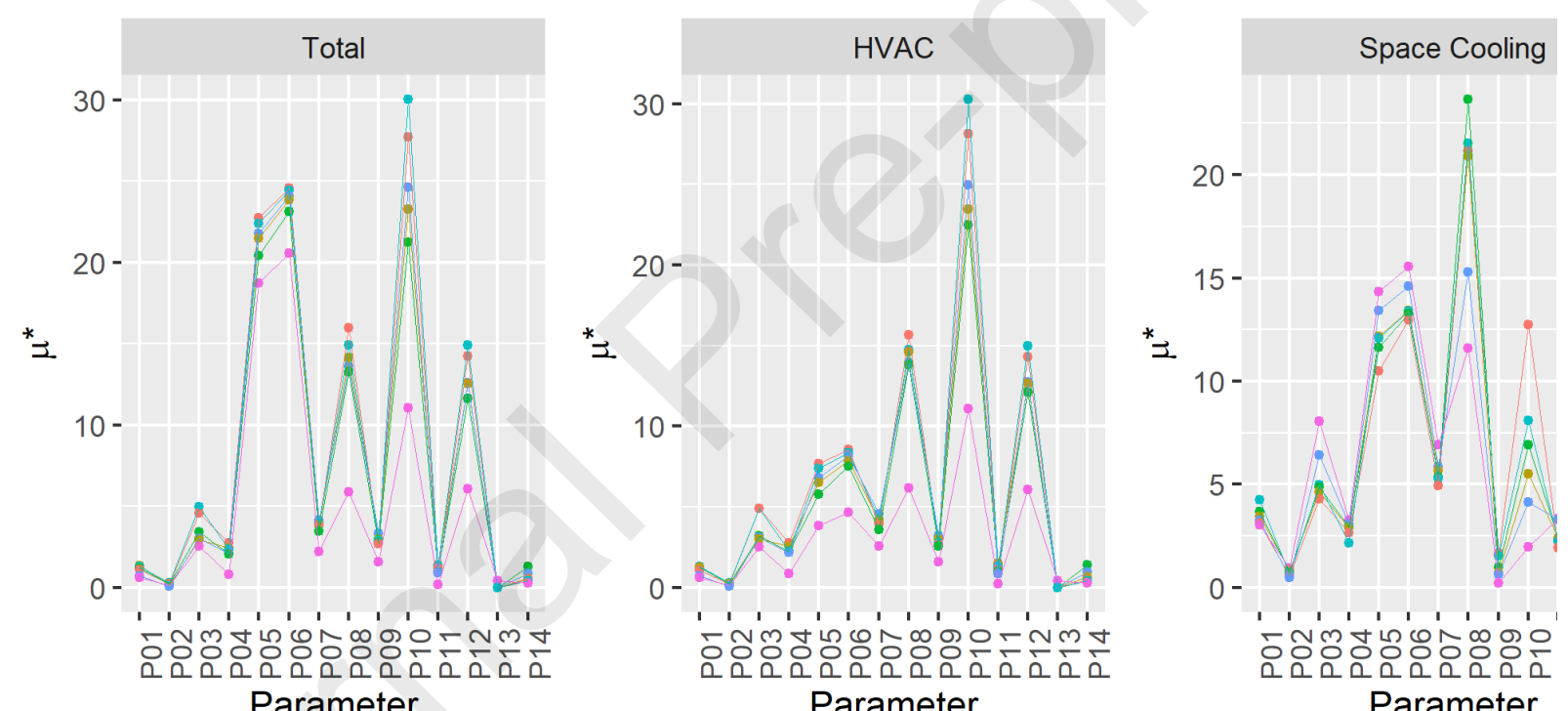

Fig. 8 - Morris EE $\mu^{*}$ indices for each input parameter relative to peak demand output results

The next section of the result analysis was concerned with evaluating the sensitivity of results regarding changes to the 14 parameters in the input space, using the Morris EE method. In Fig. 7 and Fig. 8 , the ranking order of factors is made based on the mean sensitivity indices $\left(\mu^{*}\right)$. What stands out in these figures is that the ranking order of the indices is different between different outputs, and when comparing the annual demand and the peak load. It is apparent from these results that the ranking of the sensitivity indices, in some outputs, may change between the different climates. Interestingly, results for C1-Singapore looking at total annual demand stand from the remaining location results. Similarly, results for C6-London are significantly different when exploring the total 
peak load. However, it is important to analyse these results, acknowledging that calculated Morris EE means indices are dependent on the absolute value of the output metric for each location. Thus, these differences in some locations are consistent with the previously discussed finding that annual demand for C1-Singapore is much larger and there is a lower demand for the peak in C6-London.

It is apparent from the order of the mean sensitivity value for HVAC electricity end-use results are the most sensitive to changes on parameter $\mathrm{P} 10$, ventilation rate, both for annual and peak, and at a second level by the ambient set point (P8) and the COP (P12) and then by the equipment (P6) and lighting (P5) heat gains. For total demand, these indices are only altered for parameter P06, P05 and P14, as they are the only parameters that contribute to changes in other end uses of electricity demand (lighting and equipment) beside HVAC end-use. P06 and P05 become the largest contributors for total demand paired with P10, for both annual and peak. However, the contribution of P05 and P06 compared to P10 are dependent on location. Thus, this is related to the sensitivity level of P10 for HVAC demand. So, when the sensitivity of P10 for HVAC is not large, P05 and P06 rank higher on total demand, as for most locations for annual demand and C6-London for peak demand.

Turning now to the SA of SPC, for annual demand, P05 and P06 are the largest contributors and at second stage $\mathrm{P} 03, \mathrm{P} 08, \mathrm{P} 07$ and $\mathrm{P} 14$. It is possible to verify that locations lead to larger or smaller contributions, but changes on the ranking of parameters are not significant. For Peak demand, P08 is the largest contributor, followed on a second stage by P05 and P06, and then by P10. The contribution of each parameter significantly changes between locations, especially for parameter P08 and P10. This result is somewhat surprising when compared to the contribution of the same parameters on HVAC demand.

The results of the Morris EE SA, in this study, indicate that the contribution of the different parameters is significantly related to the output variable analysed. The ranking and the value of the Morris EE indices are also clearly dependent on the time frame (annual or peak) and the location considered. In general, it seems that locations have different implications for the contribution of each parameter. The change of proportion is also evident between location and depending on if we are analysing annual or peak demand. However, the ranking provided by Morris EE method is aimed to enable a qualitative measure and not to quantify the effect of the factors on outputs [22]. Anyway, this screening method, due to the low computational costs, is suitable to identify a few influential factors among many. 
In summary, P10, P06 and P05 are the parameters that contribute the most for the sensitivity of the building model results across all locations, for both peak and annual demand and most of the output variables analysed. P08, the ambient set-point and P12-coefficient of performance of the chiller are the two next parameters that contribute more for the sensitivity of the building model, especially for HVAC end-use. Interestingly, P08 is the parameter with the largest contribution for peak SPC and the third largest for SPC annual demand after P06 and P05. P07 - occupancy density, P03 SHGC of the glazing and P14 the stretch operative annual hours have presented a significant level of contribution for the sensitivity in different output analysed. From these three parameters, P07 was selected to be further analysed on a Sobol indices analysis, as occupant behaviour is often analysed when checking the impacts on building energy performance. Thus, for the next sensitivity test, the Sobol indices analysis, P05, P06, P07, P08, P10 and P12 are selected to be tested.

\section{Sensitivity results from the Sobol method}

Annual

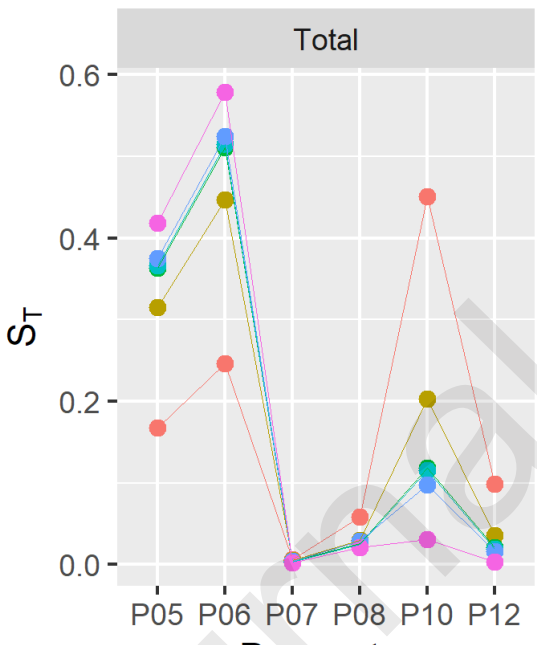

Parameter

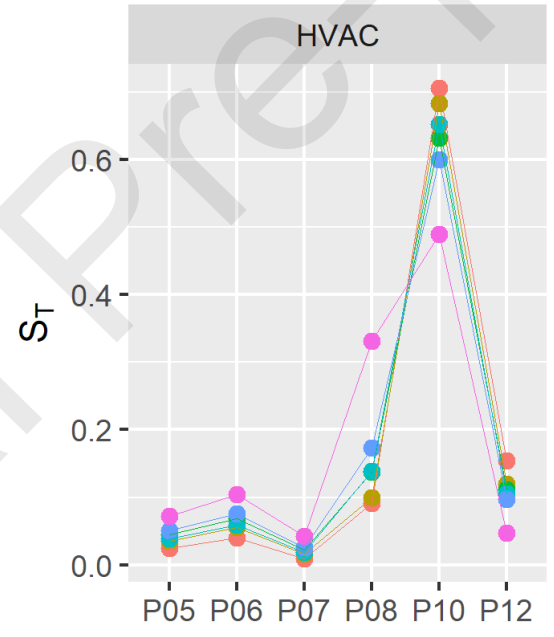

Parameter

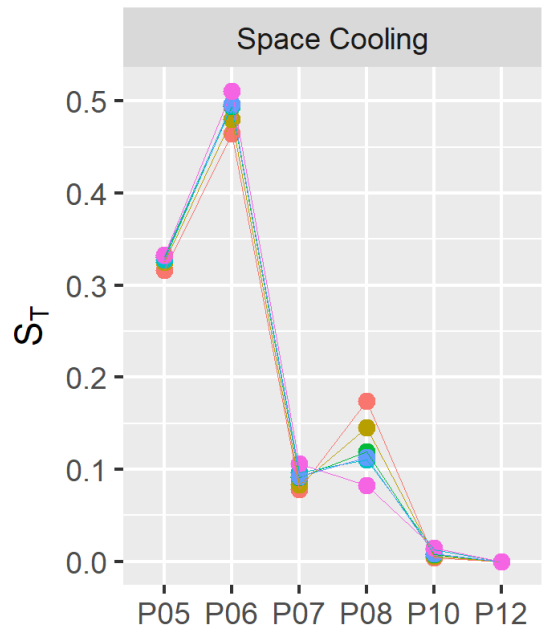

Parameter

Fig. 9 - Sobol total sensitivity indices for annual demand results 


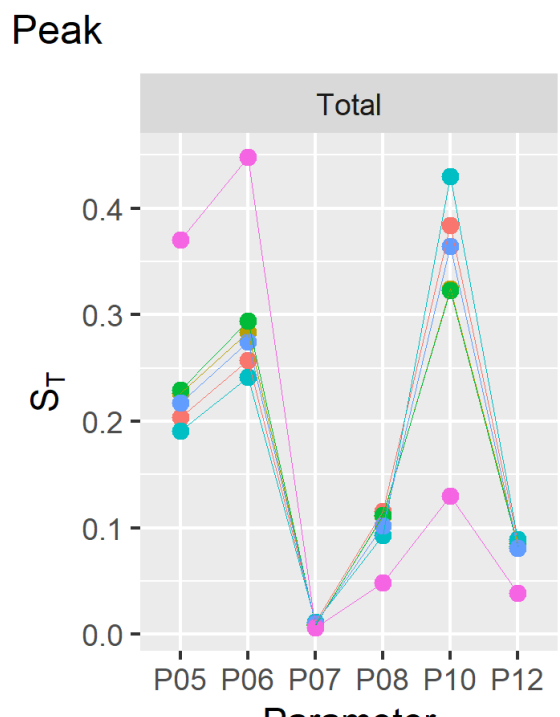

Parameter

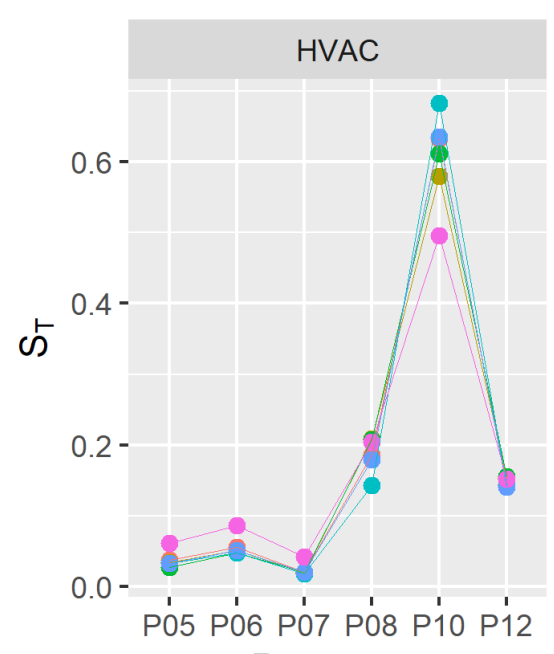

Parameter

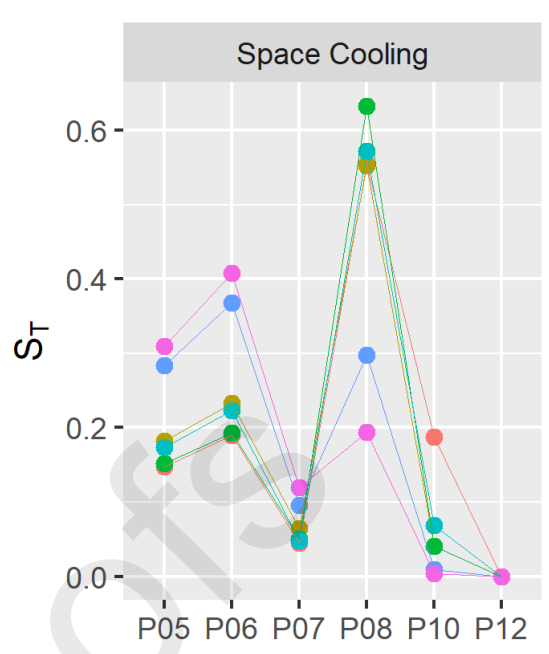

Parameter

\section{Fig. 10 - Sobol total sensitivity indices for peak demand results}

The analysis of Sobol sensitivity indices, which are shown in Fig. 9 and Fig. 10, identify that for the total annual demand, P06 and P05 are the single largest contributors, except for C1-Singapore, contributing respectively up to almost $60 \%$ and $40 \%$ for C6-London. P10 is the following parameter to contribute the most, and for C1-Singapore, it contributes almost $45 \%$. For peak demand, P10 is the single parameter that contributes the most, up to $42 \%$ in C4-Beijing. P06 and P05 follow with respectively almost $25 \%$ and $20 \%$. A comparison of the Sobol indices for HVAC demand shows that the contribution of parameters is similar between climates, especially for peak demand. P10 is the single parameter that contributes the most followed by P08 and P12. Regarding the SPC output metric, it is clear that P06 and P05 have the largest contributions for annual demand. P08 is the parameter that follows for annual, but for peak case, it is for most locations the largest contributor for change, and it can represent up to $60 \%$.

In this analysis of Sobol indices, similar trends on the importance of parameters were found relative to the findings of the results of the Morris EE method. The ranking of parameters for the different metrics and time case is similar, but better quantification of differences between contributions are possible to state. In this method, it is possible to confirm that C1-Singapore and C6-London are outliers respectively for annual and peak demand. P10 is the parameter with the largest contribution for HVAC demand, and its contribution for total demand seems to be related to the share of HVAC load on the total. Thus, this contribution is larger for peak than for annual, and it is consistently larger on locations that present a larger share of HVAC on total demand. Interestingly, for space cooling, 
P08 - the cooling set point factor presents changes on the contribution based on location. On peak demand, the contribution of P08 can be substantially reduced for a location such as C5-Lisbon and C6-London, such that P06 and P05 factors become the largest contributors. Similarly, its contribution to annual HVAC demand change is also much larger for C6-London. However, looking to the results from HVAC demand it is possible to infer that these differences are related to the share of the HVAC load on the total load.

\section{Discussion}

This study set out with the aim of examining the sensitivity of cooling demand related results in a large office building, both for annual and peak demand. For office buildings, it is clear that P10 ventilation rate is the single parameter that contributes the most for HVAC demand in buildings. Very little was found in the literature regarding the impacts of ventilation rate for cooling requirements and total electricity demand. For example, Østergård et al. [50] conclude that ventilation is the parameter with the largest contribution to the energy demand of an office building in a heating-dominated location, in Denmark. Huang et al [51] conclude that outdoor airflow rate is the third parameter that contributes the most for the energy consumption of a zero-carbon building in Hong Kong, after parameters such as skylight to roof ratio and solar heat gain coefficient of the skylight. The results presented in this study differ from [26] and [13], which conclude that occupant density in the building is the single most contributor for peak cooling sensitivity and annual cooling demand, respectively. In this study, it was concluded that P07 - occupant density has a small contribution (less than $5 \%$ ) to both peak and annual HVAC demand. This inconsistency is likely to be related to the fact that in many modelling approaches, ventilation rates are related to the occupancy of the spaces. In this study, the ventilation rate of spaces is completely decoupled from space occupancy. Some other studies have analysed the sensitivity of infiltration rates, such as [28] and [10]. However, both concluded that the contribution of infiltration rates are normally lower than the contribution of the other parameters. These findings are consistent with low sensitivity that parameter P11 - infiltration shown in this study, on the Morris EE method. A note of caution is due here since the infiltration rate range covered in this study is roughly between 0.1 to $3 \mathrm{I} \cdot \mathrm{s}^{-1} \cdot \mathrm{m}^{-2}$ (envelope surface area), between 0.03 and 1 air changes per hour on this building model. For similar infiltration rates per envelope area, the total air change rate may be much superior in buildings that present much higher ratio between envelope surface area and floor space area. In such type of buildings, infiltration rates may present much higher implications for cooling demand. 
For the design of new buildings or retrofit of buildings, the research findings can inform that it is important to focus on the ventilation rate and then for equipment and lighting densities, to reduce total electricity building peak load. To reduce annual electricity demand, equipment and lighting densities can have the largest contribution. However, for climates with constant large cooling demand throughout the whole year such as faced in Singapore, ventilation rates have the largest contribution to the annual electricity demand. For the sizing of the HVAC equipment (peak and annual HVAC electricity demand), the ventilation rate is the parameter that contributes the largest and it is followed by the ambient set-point and the coefficient of performance.

One of the initial objectives of this study was to identify the implications of different locations on the sensitivity of the cooling and total loads of an office building. This study has found that different types of climates may lead to different responses to the sensitivity of the total electricity demand. As mentioned in the literature review, not many studies have analysed the implications of different locations for the sensitivity of cooling related demand in buildings. Mechri et al. [52] identify that the value of a parameter's sensitivity index for cooling energy needs is similar across five different locations that represent significantly different climates across Italy. In this study, similar findings were achieved on the sensitivity linked to HVAC demand. However, the effects on total demand are significantly different, which is also found by Huang et al. [32]. The weather conditions significantly influence the optimal configuration of building chillers in a study of the uncertainty of cooling loads. These different findings show that it is important to have a more holistic approach to analysing the uncertainty and sensitivity of building models. Therefore, this study has analysed simultaneous different output variables and considering both peak and annual periods.

Since the study was limited to the analysis of one large office building model with a single type of HVAC system, it is not possible to extend that the findings of this study are similar to other types of buildings and different type of HVAC systems. For example, it would be important to analyse other types of archetype office buildings, as small and medium types, to explore the implications of other type HVAC systems, and different type of building forms. It is plausible that larger ratios of envelope area per floorspace area lead to different findings. The study is also limited by the lack of ability to change building model parameters as glazing area, the ratio between length and width of the building, or to expand stretch the ratio between floor space area and envelope area. The analysis of the implications of some of these parameters is important to be made, especially regarding the possible 
interactions that may exist with some parameters considered in this study. Next, the study conducted a static approach to model several parameters in the analysis, especially on HVAC parameters. A more dynamic and sparse modelling approach will probably enable to analyse the implications of smart control of detrimental parameters during peak periods. This type of modelling may be able to mimic real practices on building systems management and upgrade the impacts of the analysis. The assumptions on the limits of the uncertainty range and especially on the distribution of these ranges may lead to bias findings. Further work is required to establish the effect of uncertainty quantification assumptions, considering diversified archetypes that include more detailed and representative benchmark data. Finally, it may be interesting to analyse the implications between HVAC demand and space cooling needs, also considering the requirements specifically for sensible and latent loads.

The results presented in this study corroborate to similar findings with previous works, which links equipment and lighting density loads as the parameters that contribute the most for total annual electricity demand on buildings. These results are consistent with De Wilde et al. [27] that indicate that lighting and equipment are the largest contributors for the overheating in current weather conditions in Birmingham, UK. The findings of this study are also in agreement with findings in De Wilde et al. [27], that show that in future warmer climates the contribution of these two factors is reduced, as the cooling needs increase with increasing temperatures.

The present results of this study are significant in at least two major respects. First, the change in peak demand can be significantly larger than it is for annual demand, especially on climates with hot summers and significant seasonal patterns (C2-C3-C4-C5). Second, the contribution of different parameters for the HVAC demand is similar between locations, for both annual and peak demands. However, the contribution for total electricity demand is strongly affected by the location, which is caused by the share of HVAC loads on the total demand. Finally, it is clear that for both annual and peak demand, ventilation rate $-\mathrm{P} 10$ is the single parameter that contributes the most for HVAC demand, and consequently for total demand. P06 and P05 are the contributors that follow for total demand, and together they can still contribute to more than $50 \%$ of demand.

\section{Conclusion}

The present research aimed to examine the sensitivity of cooling demand related results (total electricity demand, HVAC end-use and space cooling) in a large office building, so identifying the parameters that have a larger contribution to these different results. In addition, it examines the 
implications of different type of climates to the uncertainty in these different output results and the sensitivity of the different parameters for each result. The second aim of this paper was to investigate the difference between the effects of annual and peak analysis.

This study has found that generally, the changes are more significant for peak demand than for annual demand. This is the case for most of the climates, for total and HVAC loads, as for example the CV on total peak demand is around $25 \%$ and $21 \%$ for total annual demand. The exceptions are C1-Singapore and C6-London, where the CV of peak demand is just slightly larger than annual. The research has also shown that the implications are different for the different outputs analysed, such that the CV of space cooling and the different HVAC end-use varies differently. Also, the contribution of each parameter is significantly different when considering the different outputs and periods. The variation of the importance of parameters can be substantially different, depending on the climate considered and the output variable analysed. For example, P10 is the most important contributor for changes in HVAC peak demand, with a similar level of contributions, but the implication for total peak load is significantly different depending on the climate.

The study contributes to the understanding of the implications of the uncertainty of building simulation assumptions on electricity consumption mainly driven by space cooling demand. This study identifies that the ventilation rate of a building $(\mathrm{P} 10)$ is the parameter that contributes the largest for the electricity demand of the HVAC end-use, between $50 \%$ to $70 \%$ of the change $\left(\mathrm{S}_{\mathrm{T}}\right)$, both for annual and peak demand. Regarding the effect on total electricity demand, ventilation rate is still one of the most important factors, but P05 and P06 also become a major contributor to the sensitivity of the total demand. This is even more evident, for annual demand, where P05 and P06 together can contribute to up to $90 \%$ of the changes in total annual electricity demand. Different results were reported according to the different locations analysed, so the contribution of P05 and P06 is decreased the largest the proportion of HVAC end-use is in the total load, contributing roughly $40 \%$ for a location such as C1-Singapore. Therefore, tropical climates such as C1-Singapore, with stable monthly loads lead to many different conclusions than all the other locations analysed. Moreover, this study also provides insight on capacity design for building cooling systems, which is significant in comparison with reducing energy use of buildings. The cooling systems in various locations should be carefully decided based on the combination of uncertainty and sensitivity analysis. The sensitivity analysis can 
be used to determine the main factor influencing peak cooling loads, while the uncertainty analysis can provide reliability of cooling system design by considering uncertain factors.

A natural progression of this work is to make similar sensitivity analyses in small and medium reference office buildings. Further work also needs to be done to establish the implications of changes in the type of HVAC and the type of operation considered, to the sensitivity and uncertainty of the model outputs, especially on how this could alter the relationship with peak demand. One potential challenge is to develop and adapt an office building model that can automatically iterate the form of a model, maintaining all the geometry constrains between internal zones, so the whole integrated simulation of the building can be performed considering specific alterations of the building geometry (glazing areas, w-I ratios, envelope ratios). Further research should focus on determining the implications of considering a different type of statistical distributions of the input parameters and the limits of the ranges considered. Another important practical implication is that future research studying the sensitivity on cooling demand of buildings should undertake more holistic approach and overview the impacts over annual, peak spans, and the implications to HVAC end-use and the total final energy demand.

Acknowledgment: Vasco Zeferina acknowledges financial support from EPSRC (EP/L016141/1) through the Power Networks Centre for Doctoral Training.

CRediT author statement: Vasco Zeferina: Conceptualisation, Methodology, Software, Formal analysis, Visualisation, Writing - Original Draft, Writing - Review \& Editing; Ruth Wood: Supervision, Writing - Review \& Editing; Rodger Edwards: Supervision, Writing - Review \& Editing; Wei Tian: Writing - Review \& Editing

\section{Reference List:}

[1] J.L.M.. Hensen, R. Lamberts, Introduction to building performance simulation, in: J.L.M.. Hensen, R. Lamberts (Eds.), Build. Perform. Simul. Des. Oper., First, Routledge, London, 2011. https://doi.org/10.4324/9780203891612.

[2] P. de Wilde, Building Performance Analysis, 2018. https://doi.org/10.1002/9781119341901.

[3] T. Hong, J. Langevin, K. Sun, Building simulation: Ten challenges, Build. Simul. 11 (2018) 871-898. https://doi.org/10.1007/s12273-018-0444-x.

[4] P. de Wilde, Ten questions concerning building performance analysis, Build. Environ. 153 (2019) 110-117. https://doi.org/10.1016/j.buildenv.2019.02.019.

[5] J.A. Clarke, J.L.M. Hensen, Integrated building performance simulation: Progress, prospects and requirements, Build. Environ. 91 (2015) 294-306. 
https://doi.org/10.1016/j.buildenv.2015.04.002.

[6] P. De Wilde, The gap between predicted and measured energy performance of buildings: A framework for investigation, Autom. Constr. 41 (2014) 40-49. https://doi.org/10.1016/j.autcon.2014.02.009.

[7] A. Beizaee, K.J. Lomas, S.K. Firth, National survey of summertime temperatures and overheating risk in English homes, Build. Environ. 65 (2013) 1-17. https://doi.org/10.1016/j.buildenv.2013.03.011.

[8] M. Kolokotroni, X. Ren, M. Davies, A. Mavrogianni, London's urban heat island: Impact on current and future energy consumption in office buildings, Energy Build. 47 (2012) 302-311. https://doi.org/10.1016/j.enbuild.2011.12.019.

[9] S. Petersen, M.H. Kristensen, M.D. Knudsen, Prerequisites for reliable sensitivity analysis of a high fidelity building energy model, Energy Build. 183 (2019) 1-16. https://doi.org/10.1016/j.enbuild.2018.10.035.

[10] P. De Wilde, W. Tian, Predicting the performance of an office under climate change: A study of metrics, sensitivity and zonal resolution, Energy Build. 42 (2010) 1674-1684. https://doi.org/10.1016/j.enbuild.2010.04.011.

[11] F. Domínguez-Muñoz, J.M. Cejudo-López, A. Carrillo-Andrés, Uncertainty in peak cooling load calculations, Energy Build. 42 (2010) 1010-1018.

https://doi.org/10.1016/j.enbuild.2010.01.013.

[12] B. Eisenhower, Z. O’Neill, V.A. Fonoberov, I. Mezic, I. Mezi??, Uncertainty and sensitivity decomposition of building energy models, J. Build. Perform. Simul. 5 (2012) 171-184. https://doi.org/10.1080/19401493.2010.549964.

[13] Y. Sun, L. Gu, C.F.J. Wu, G. Augenbroe, Exploring HVAC system sizing under uncertainty, Energy Build. 81 (2014) 243-252.

https://doi.org/10.1016/j.enbuild.2014.06.026.

[14] P. Huang, G. Huang, G. Augenbroe, Sizing heating, ventilating, and air-conditioning systems under uncertainty in both load-demand and capacity-supply side from a lifecycle aspect, Sci. Technol. Built Environ. 23 (2017) 367-381. https://doi.org/10.1080/23744731.2016.1260409.

[15] K. Menberg, Y. Heo, R. Choudhary, Sensitivity analysis methods for building energy models: Comparing computational costs and extractable information, Energy Build. 133 (2016) 433-445. https://doi.org/10.1016/j.enbuild.2016.10.005.

[16] A. American Society of Heating, Refrigerating and Air-Conditioning Engineers, 2013 ASHRAE Handbook - Fundamentals, 7th ed., ASHRAE, 2013, Atlanta, 2013.

[17] M. Kavgic, T. Hilliard, L. Swan, Opportunities for implementation of MPC in commercial buildings, Energy Procedia. 78 (2015) 2148-2153. https://doi.org/10.1016/j.egypro.2015.11.300.

[18] A. Abela, L. Hamilton, R. Hitchin, C. Pout, A. Lewry, Study on Energy Use by AirConditioning, 2016. https://www.bre.co.uk/filelibrary/pdf/projects/aircon-energyuse/StudyOnEnergyUseByAirConditioningFinalReport.pdf.

[19] F.R. Wood, D. Calverley, S. Glynn, S. Mander, C. Walsh, J. Kuriakose, F. Hill, M. Roeder, The impacts of climate change on UK energy demand, Infrastruct. Asset Manag. 2 (2015) 107-119. https://doi.org/10.1680/iasma.14.00039.

[20] A. Saltelli, M. Ratto, F. Campolongo, J. Cariboni, D. Gatelli, Global Sensitivity Analysis . The Primer, 2008. https://doi.org/10.1002/9780470725184.ch6. 
[21] W. Tian, Y. Heo, P. de Wilde, Z. Li, D. Yan, C.S. Park, X. Feng, G. Augenbroe, A review of uncertainty analysis in building energy assessment, Renew. Sustain. Energy Rev. 93 (2018) 285-301. https://doi.org/10.1016/j.rser.2018.05.029.

[22] W. Tian, A review of sensitivity analysis methods in building energy analysis, Renew. Sustain. Energy Rev. 20 (2013) 411-419. https://doi.org/10.1016/j.rser.2012.12.014.

[23] B. looss, P. Lemaître, A Review on Global Sensitivity Analysis Methods, in: M.C. Dellino G. (Ed.), Oper. Res. Sci. Interfaces Ser. B. Ser. (ORCS, Vol. 59), Springer, Boston, MA, 2015: pp. 101-122. https://doi.org/10.1007/978-1-4899-7547-8_5.

[24] V. Zeferina, R. Wood, J. Xia, R. Edwards, Sensitivity analysis of a simplified office building, J. Phys. Conf. Ser. 1343 (2019). https://doi.org/10.1088/17426596/1343/1/012129.

[25] M. Labat, K. Attonaty, Numerical estimation and sensitivity analysis of the energy demand for six industrial buildings in France, J. Build. Perform. Simul. 11 (2018) 223240. https://doi.org/10.1080/19401493.2017.1322637.

[26] W. Tian, P. de Wilde, Z. Li, J. Song, B. Yin, Uncertainty and sensitivity analysis of energy assessment for office buildings based on Dempster-Shafer theory, Energy Convers. Manag. 174 (2018) 705-718. https://doi.org/10.1016/j.enconman.2018.08.086.

[27] P. de Wilde, W. Tian, Identification of key factors for uncertainty in the prediction of the thermal performance of an office building under climate change, Build. Simul. 2 (2009) 157-174. https://doi.org/10.1007/s12273-009-9116-1.

[28] W. Tian, J. Song, Z. Li, P. de Wilde, Bootstrap techniques for sensitivity analysis and model selection in building thermal performance analysis, Appl. Energy. 135 (2014) 320-328. https://doi.org/10.1016/j.apenergy.2014.08.110.

[29] Q. Wang, Y. Pan, Y. Fu, Z. Huang, W. Zuo, P. Xu, A simulation-based method for air loop balancing and fan sizing using uncertainty and sensitivity analysis, Build. Simul. 12 (2019) 247-258. https://doi.org/10.1007/s12273-018-0471-7.

[30] W. Gang, S. Wang, F. Xiao, D.C. Gao, Robust optimal design of building cooling systems considering cooling load uncertainty and equipment reliability, Appl. Energy. 159 (2015) 265-275. https://doi.org/10.1016/j.apenergy.2015.08.070.

[31] Y. Sun, P. Huang, G. Huang, A multi-criteria system design optimization for net zero energy buildings under uncertainties, Energy Build. 97 (2015) 196-204. https://doi.org/10.1016/j.enbuild.2015.04.008.

[32] P. Huang, G. Huang, G. Augenbroe, S. Li, Optimal configuration of multiple-chiller plants under cooling load uncertainty for different climate effects and building types, Energy Build. 158 (2018) 684-697. https://doi.org/10.1016/j.enbuild.2017.10.040.

[33] V. Zeferina, C. Birch, R. Edwards, R. Wood, Sensitivity analysis of peak and annual space cooling load at simplified office dynamic building model, E3S Web Conf. 111 (2019) 04038. https://doi.org/10.1051/e3sconf/201911104038.

[34] S. Moffatt, Methods for Evaluating the Environmental Performance of Building Stocks, 2004. http://www.iisbe.org/annex31/index.html.

[35] M. Deru, K. Field, D. Studer, K. Benne, B. Griffith, P. Torcellini, B. Liu, M. Halverson, D. Winiarski, M. Rosenberg, M. Yazdanian, J. Huang, D. Crawley, U.S. Department of Energy commercial reference building models of the national building stock, Publ. (2011) 1-118. https://doi.org/NREL Report No. TP-5500-46861. 
[36] CIBSE, CIBSE Guide F - Energy efficiency in buildings, 2012th ed., CIBSE, London, 2012. https://www.cibse.org/Knowledge/knowledgeitems/detail?id=a0q2000000817oTAAS.

[37] D.B. Crawley, L.K. Lawrie, F.C. Winkelmann, W.F. Buhl, Y.J. Huang, C.O. Pedersen, R.K. Strand, R.J. Liesen, D.E. Fisher, M.J. Witte, J. Glazer, EnergyPlus: creating a new-generation building energy simulation program, Energy Build. 33 (2001) 319331. https://doi.org/10.1016/S0378-7788(00)00114-6.

[38] I. Korolija, L. Marjanovic-Halburd, Y. Zhang, V.I. Hanby, UK office buildings archetypal model as methodological approach in development of regression models for predicting building energy consumption from heating and cooling demands, Energy Build. 60 (2013) 152-162. https://doi.org/10.1016/j.enbuild.2012.12.032.

[39] B. looss, A. Janon, G. Pujol, F.W. Bertrand looss, Alexandre Janon and Gilles Pujol, with contributions from Baptiste Broto, Khalid Boumhaout, Sebastien Da Veiga,

Thibault Delage, Jana Fruth, Laurent Gilquin, Joseph Guillaume, Loic Le Gratiet, Paul Lemaitre, Amandine Marrel, Anouar Meynaou, sensitivity: Global Sensitivity Analysis of Model Outputs, (2020). https://cran.r-project.org/package=sensitivity.

[40] Y. Zhang, "Parallel" EnergyPlus and the Development of a Parametric Analysis Tool, in: Elev. Int. IBPSA Conf., 2009: pp. 1382-1388.

http://www.ibpsa.org/proceedings/BS2009/BS09_1382_1388.pdf.

[41] S. Wilcox, W. Marion, Users manual for TMY3 data sets, Renew. Energy. (2008) 51. https://doi.org/NREL/TP-581-43156.

[42] S.H. Kim, G. Augenbroe, Uncertainty in developing supervisory demand-side controls in buildings: A framework and guidance, Autom. Constr. 35 (2013) 28-43. https://doi.org/10.1016/j.autcon.2013.02.001.

[43] B.D. Lee, Y. Sun, G. Augenbroe, C.J.J. Paredis, Towards better prediction of building performance : a workbench to analyze uncertainty in building simulation, in: Proc.

BS2013 13th Conf. Int. Build. Perform. Simul. Assoc., 2013: pp. 1231-1238.

[44] Y. Sun, Y. Heo, M.H.Y. Tan, H. Xie, C.F.J. Wu, G. Augenbroe, Uncertainty quantification of microclimate variables in building energy models, J. Build. Perform. Simul. 7 (2014) 17-32. https://doi.org/10.1080/19401493.2012.757368.

[45] Y. Sun, G. Augenbroe, Urban heat island effect on energy application studies of office buildings, Energy Build. 77 (2014) 171-179.

https://doi.org/10.1016/j.enbuild.2014.03.055.

[46] Chartered Institution of Building Services Engineers, CIBSE Guide B2 - Ventilation and ductwork, 2016th ed., Chartered Institution of Building Services Engineers, London, 2016. https://www.cibse.org/knowledge/knowledgeitems/detail ?id=a0q20000008JuB7AAK.

[47] A. American Society of Heating, Refrigerating and Air-Conditioning Engineers, 62.1 User's Manual: ANSI/ASHRAE Standard 62.1-2007: Ventilation for Acceptable Indoor Air Quality, American Society of Heating, Refrigerating and Air-Conditioning Engineers, 2007, 2007. https://www.ashrae.org/technicalresources/bookstore/standards-62-1-62-2.

[48] F. Sarrazin, F. Pianosi, T. Wagener, Global Sensitivity Analysis of environmental models: Convergence and validation, Environ. Model. Softw. 79 (2016) 135-152. https://doi.org/10.1016/j.envsoft.2016.02.005.

[49] B.I. and J.-M.M. M. Baudin, K. Boumhaout, T. Delage, Numerical stabilit3 of Sobol' 
indices estimation formula, in: 8th Int. Conf. Sensit. Anal. Model Output, 2016: pp. 5051. https://samo2016.sciencesconf.org/data/pages/Proceedings_Samo_2016.pdf.

[50] T. Østergård, R.L. Jensen, S.E. Maagaard, Early Building Design: Informed decisionmaking by exploring multidimensional design space using sensitivity analysis, Energy Build. 142 (2017) 8-22. https://doi.org/10.1016/j.enbuild.2017.02.059.

[51] H. Li, S. Wang, H. Cheung, Sensitivity analysis of design parameters and optimal design for zero/low energy buildings in subtropical regions, Appl. Energy. 228 (2018) 1280-1291. https://doi.org/10.1016/j.apenergy.2018.07.023.

[52] H.E. Mechri, A. Capozzoli, V. Corrado, USE of the ANOVA approach for sensitive building energy design, Appl. Energy. 87 (2010) 3073-3083. https://doi.org/10.1016/j.apenergy.2010.04.001.

A. Appendices

A.1Base Cases

a) Annual

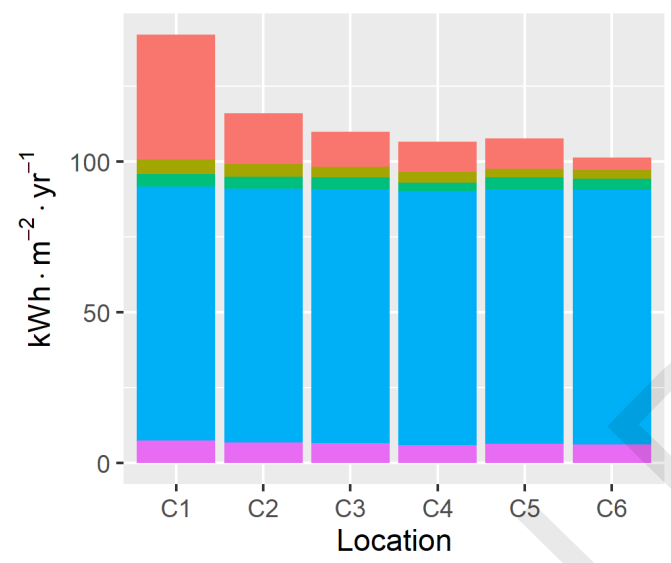

b) Peak

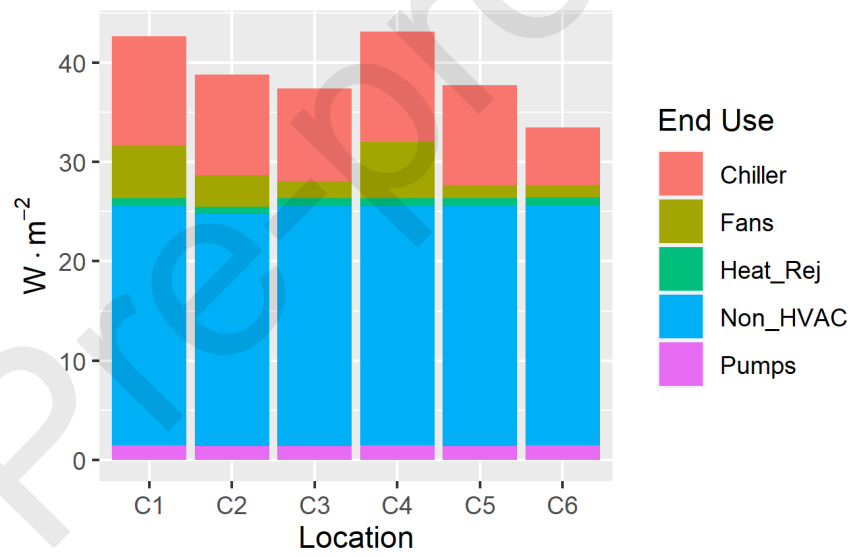

Fig A.1-1 - Electricity End-Use consumption for annual (a) and peak demand (b) 
A.2 Coefficient of Variation (cv)

Morris $c_{v}$, by end-use

- Annual - Peak
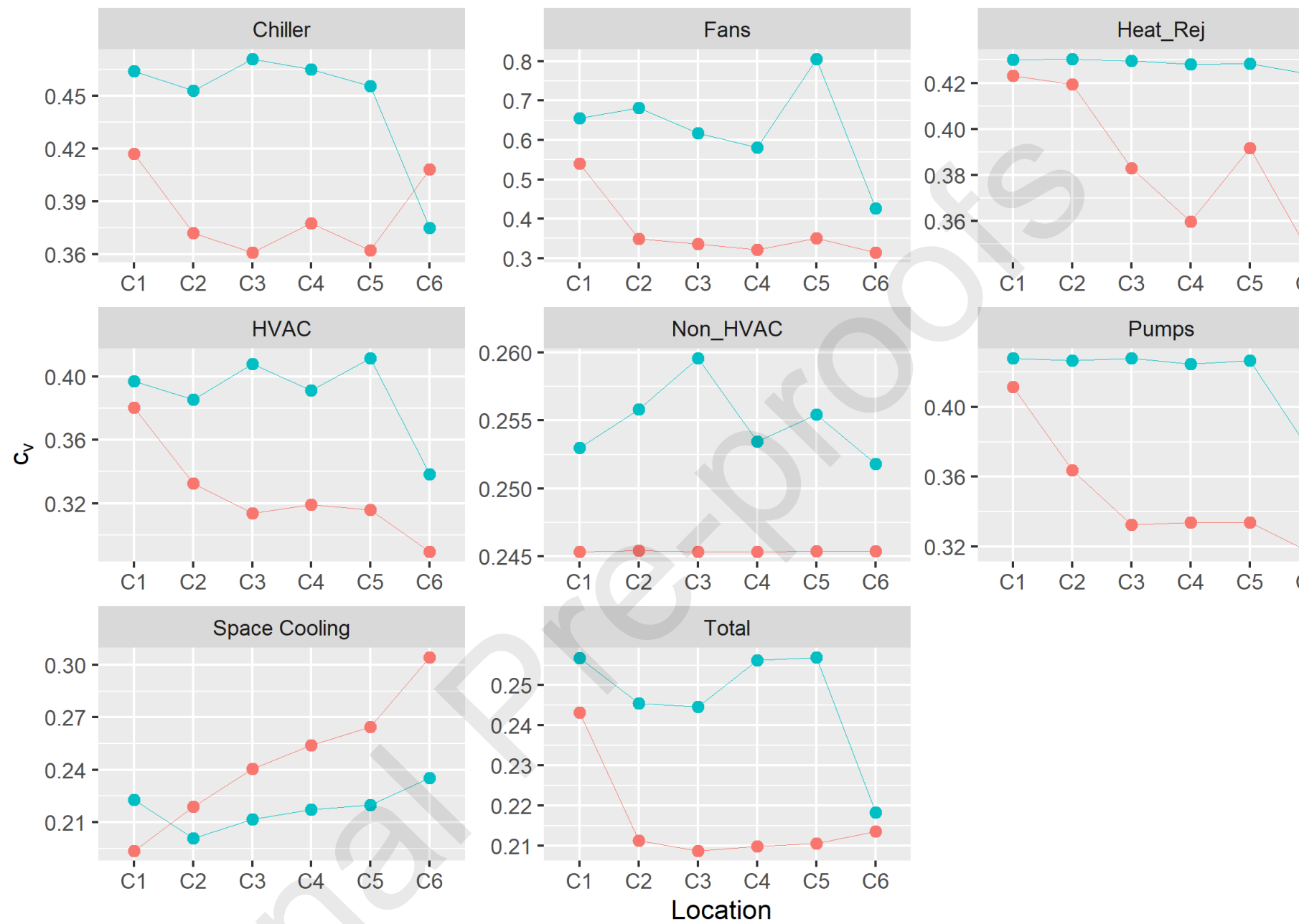

Fig A.2-1 - Coefficient of variation by variable in Morris sample 


\section{Sobol $\mathrm{C}_{\mathrm{v}}$, by end-use}

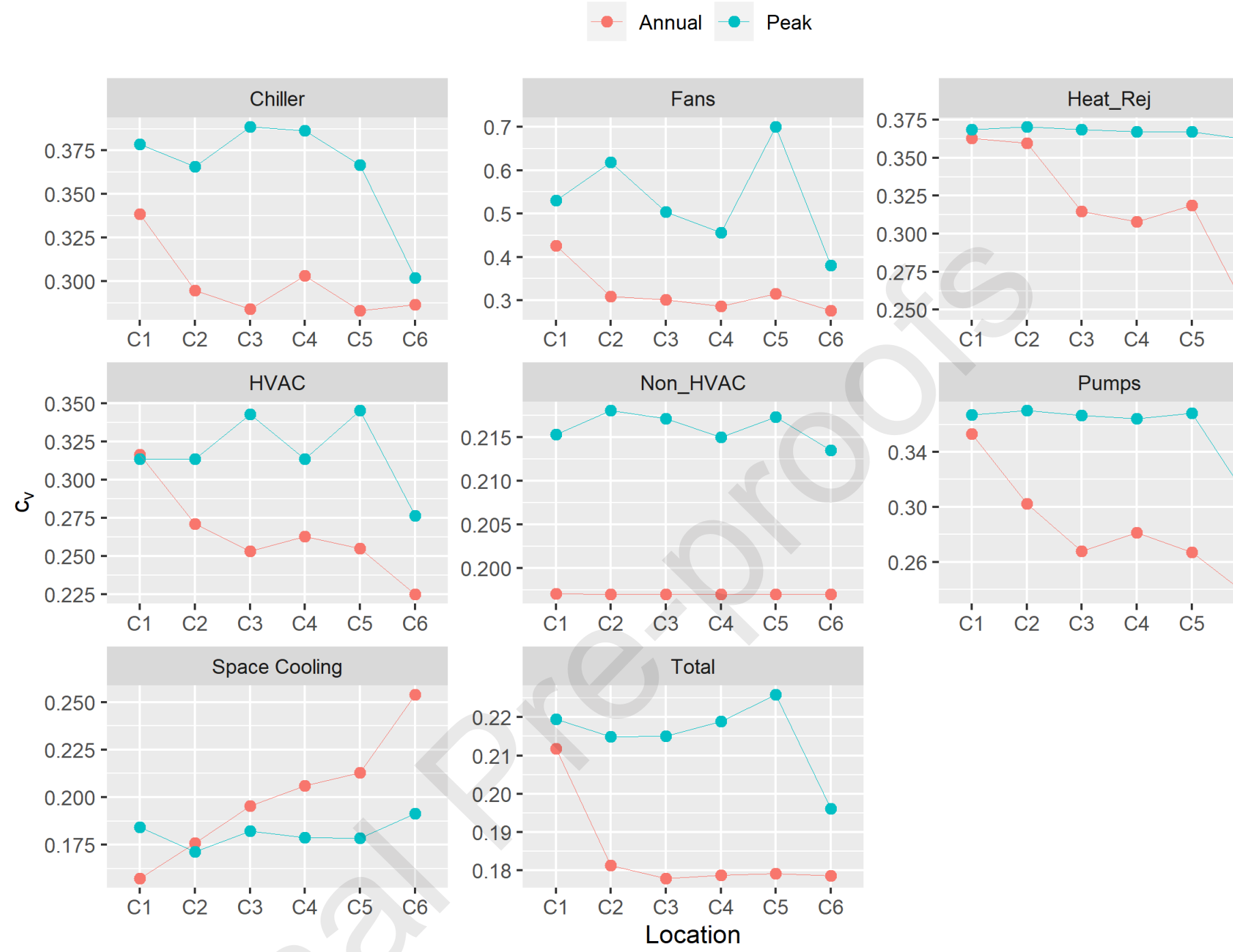

Fig A.2-2 - Coefficient of variation by variable in Sobol sample 


\section{Morris $\mathrm{c}_{\mathrm{v}}$}

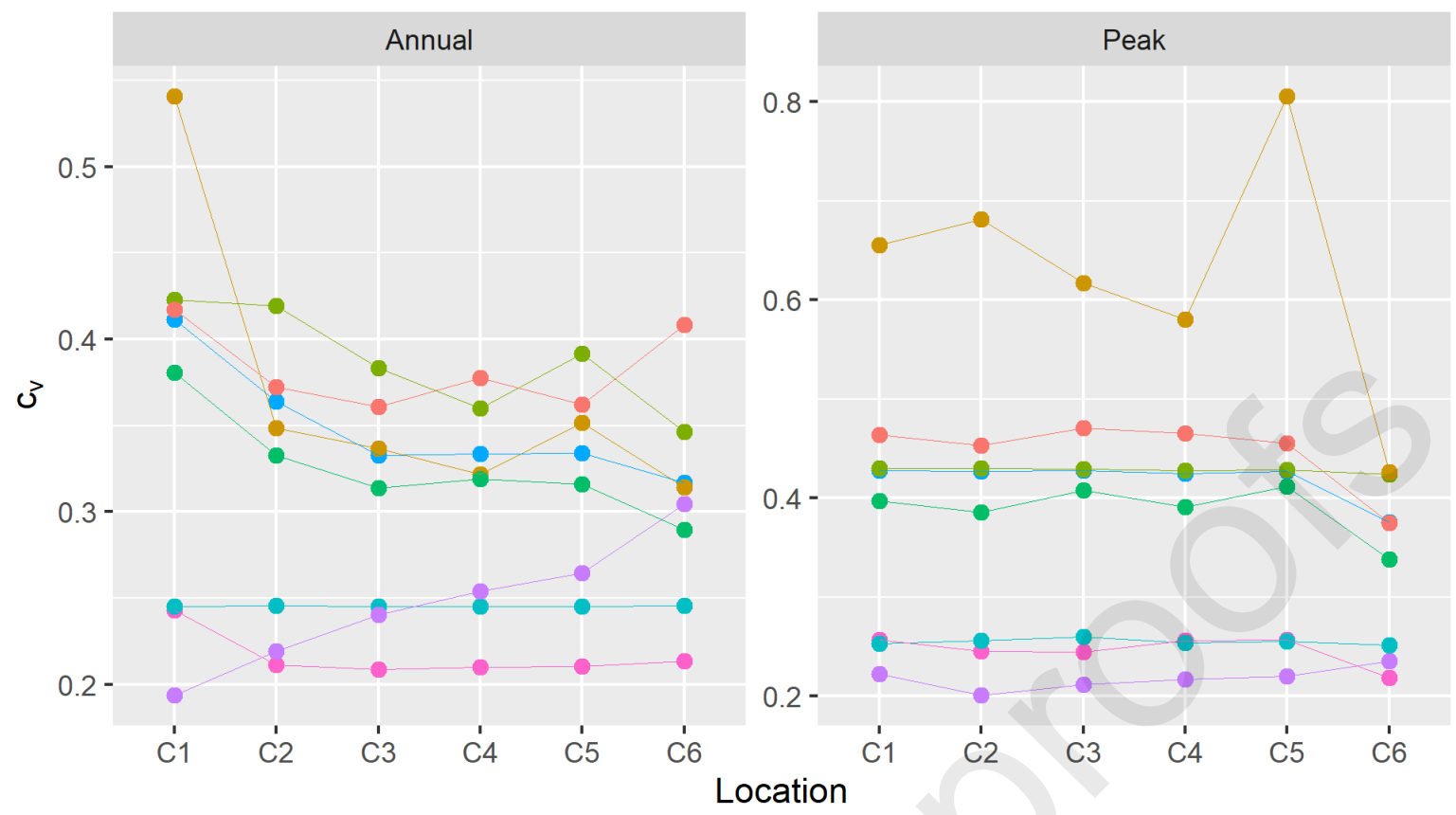

End Use

- Chiller

- Fans

- Heat_Rej

- HVAC

- Non_HVAC

- Pumps

- Space Cool

- Total

Fig A.2-3 - Coefficient of variation in Morris sample

Sobol $c_{v}$

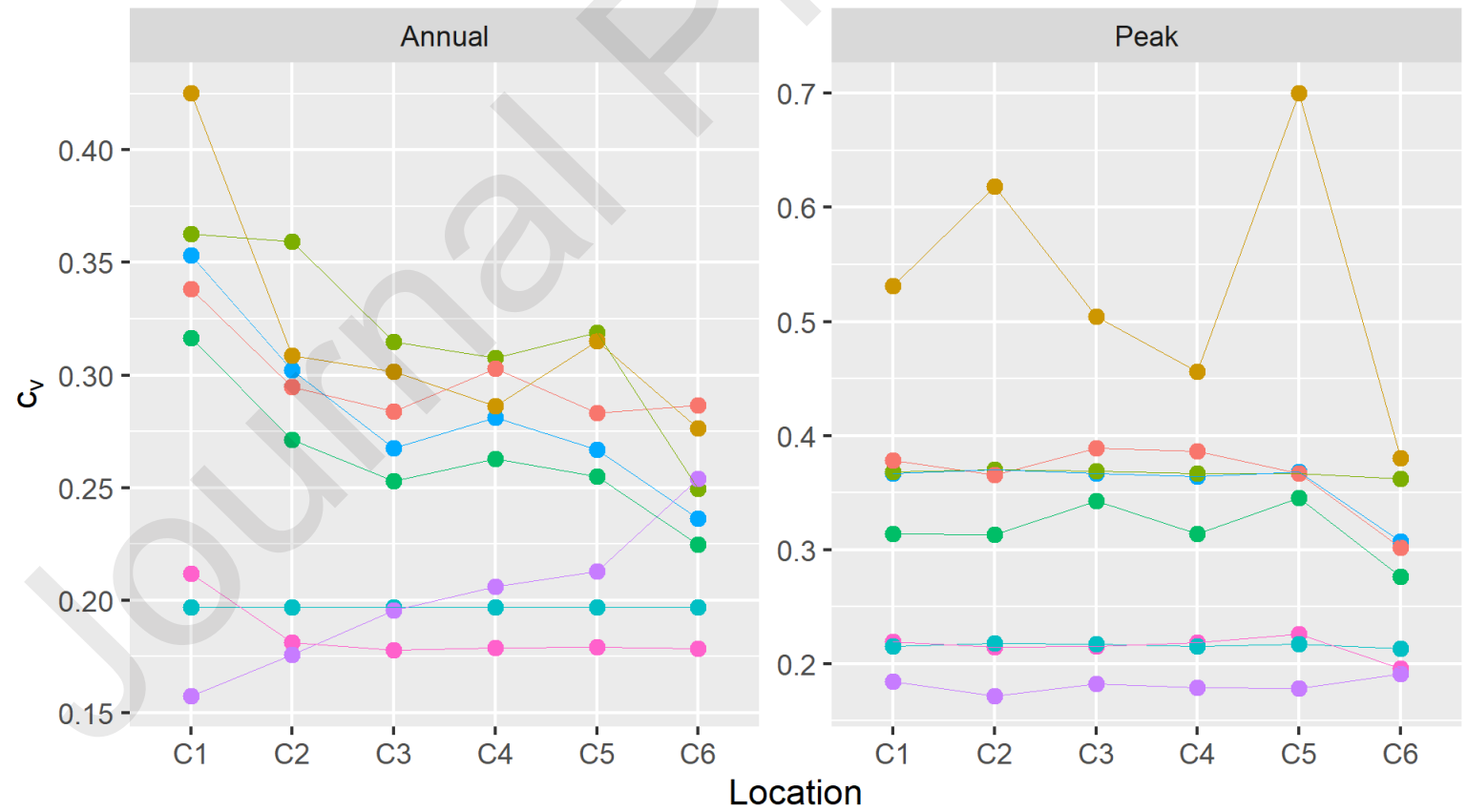

End Use

- Chiller

- Fans

- Heat_Rej

- HVAC

- Non_HVAC

- Pumps

- Space Coo

- Total

Fig A.2-4 - Coefficient of variation in Sobol sample 
A.3 Morris

\section{Annual}
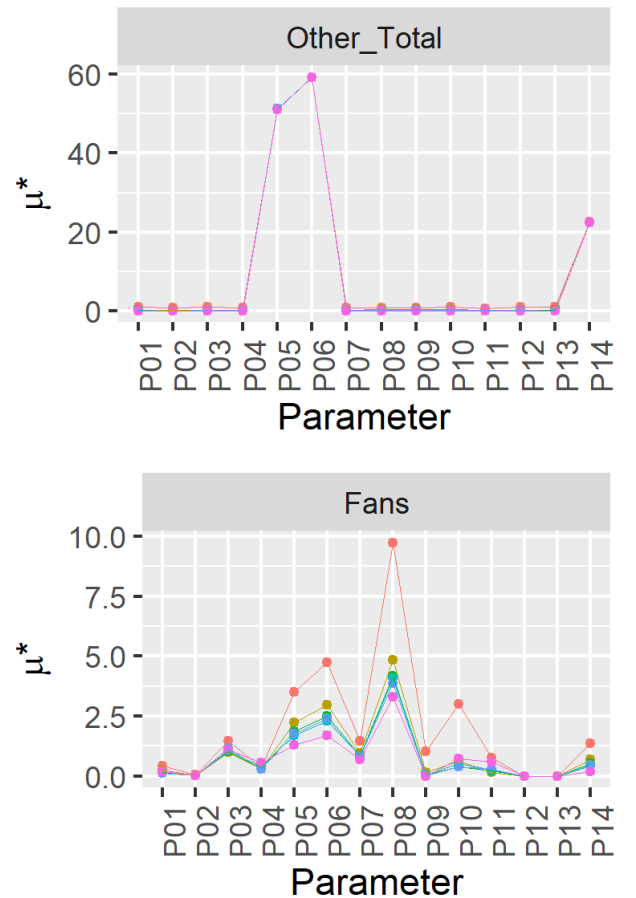
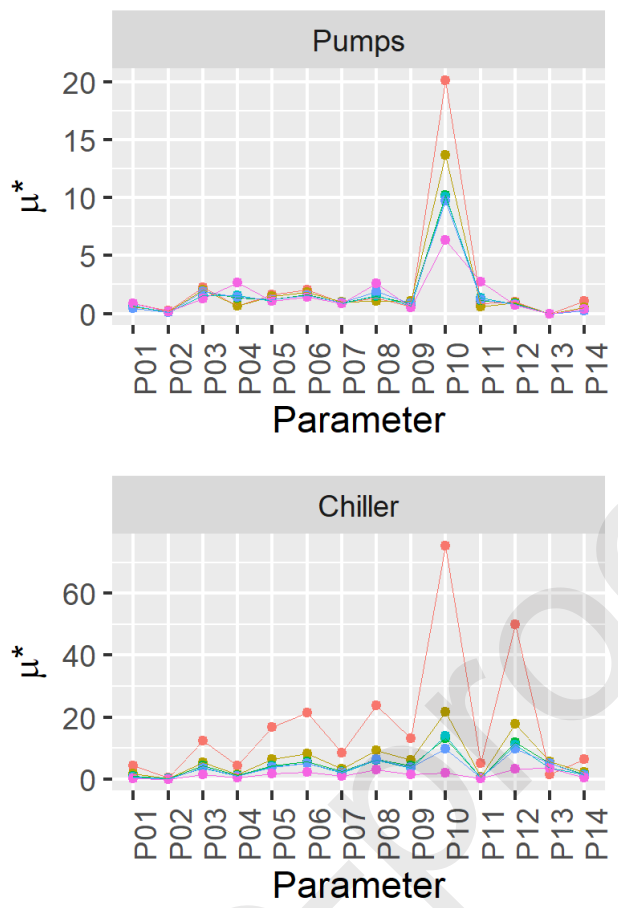

Location

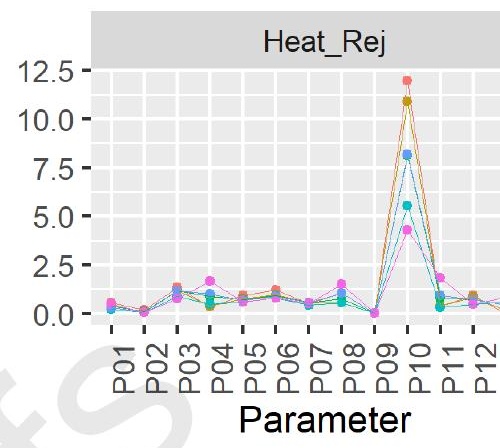

HVAC

$100-$

$75-$

* $=50-$

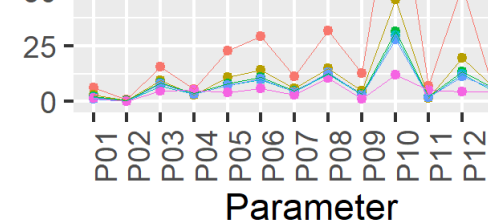


Fig A.3-1-Morris EE $\mu^{*}$ indices for HVAC end-use and other electricity end-use relative to annual demand output results Peak

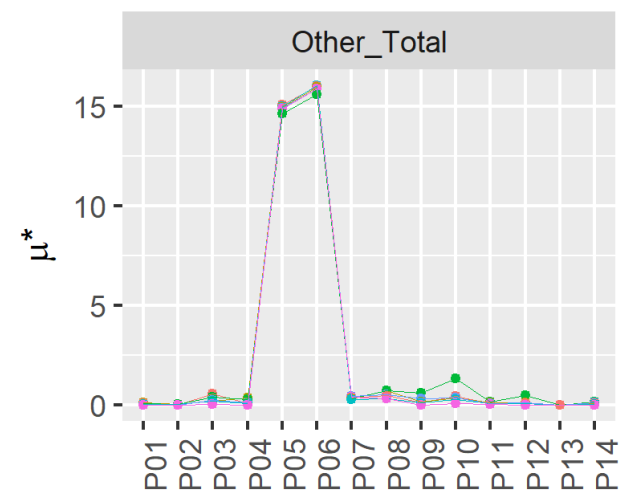

Parameter

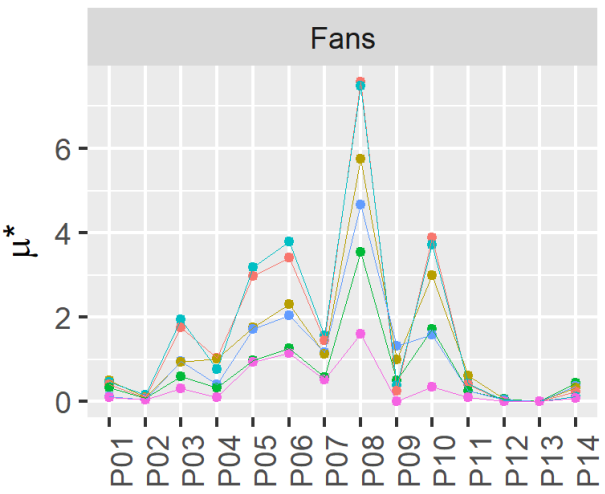

Parameter

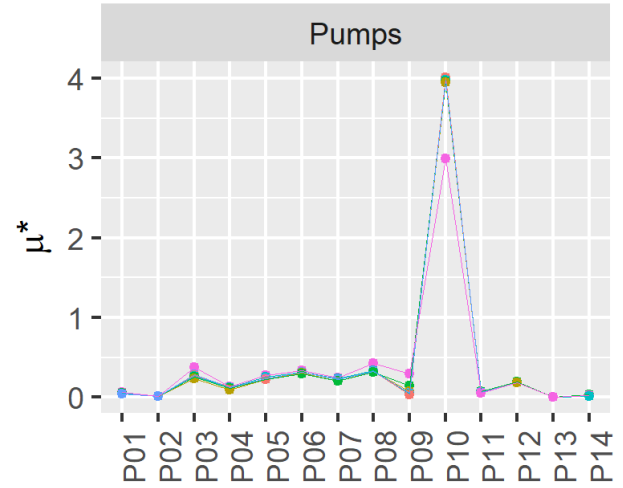

Parameter

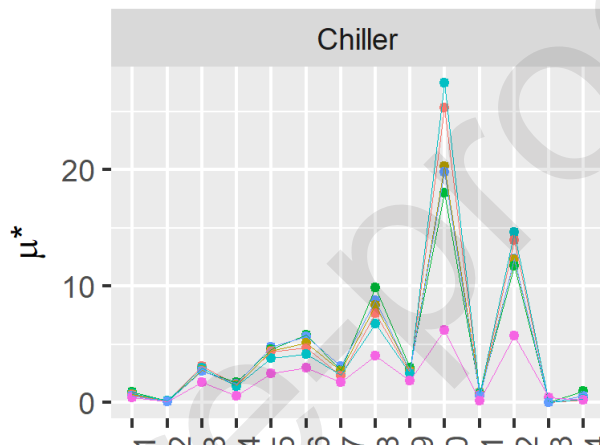

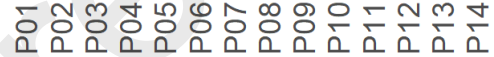

Parameter

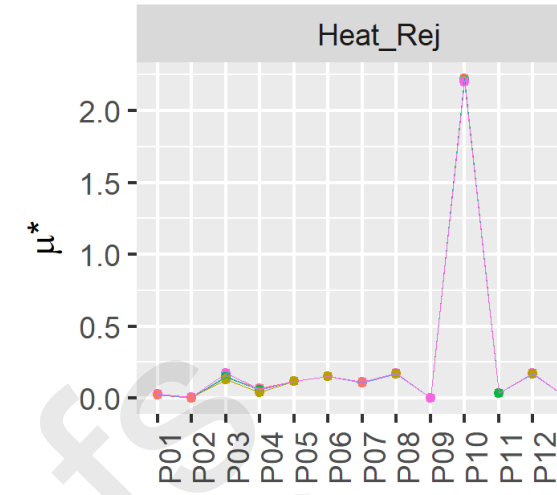

Parameter

HVAC

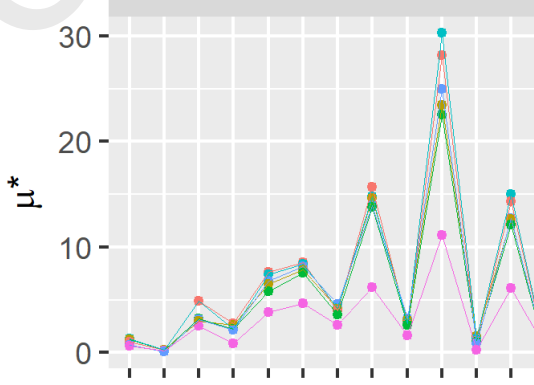

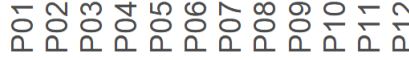

Parameter

$$
\begin{aligned}
& \text { Location } \rightarrow \mathrm{C} 1 \rightarrow \mathrm{C} 3 \rightarrow \mathrm{C} 5 \\
& \mathrm{C} 2 \rightarrow \mathrm{C} 4 \rightarrow \mathrm{C} 6
\end{aligned}
$$

Fig A.3-2 - Morris EE $\mu^{*}$ indices for HVAC end-use and other electricity end-use relative to peak demand output results

A.4 Energy efficiency ratio for Base models and Morris mean values

\begin{tabular}{|c|c|c|c|c|c|c|c|}
\hline \multicolumn{4}{|c|}{ Table A.4-1 - Base cases annual demand [kWh.m-2.yr-1] } & \multicolumn{4}{|c|}{ Table A.4-2 - Base cases peak demand [W.m-2] } \\
\hline Climate & HVAC & SPC & EER & Climate & HVAC & SPC & EER \\
\hline C1 & 57.7 & 109.2 & 1.9 & C1 & 18.5 & 36.9 & 2.0 \\
\hline $\mathrm{C} 2$ & 31.6 & 89.9 & 2.8 & $\mathrm{C} 2$ & 15.5 & 40.1 & 2.6 \\
\hline C3 & 25.5 & 72.9 & 2.9 & C3 & 13.3 & 41.1 & 3.1 \\
\hline C4 & 22.2 & 62.5 & 2.8 & C4 & 19.0 & 38.4 & 2.0 \\
\hline C5 & 23.2 & 64.6 & 2.8 & C5 & 13.6 & 32.3 & 2.4 \\
\hline C6 & 16.8 & 42.3 & 2.5 & C6 & 9.3 & 29.9 & 3.2 \\
\hline
\end{tabular}




\begin{tabular}{|cccc|ccccc|}
\hline \multicolumn{3}{|c|}{ Table A.4-3 -Morris mean peak demand $[$ W.m-2] } & & \multicolumn{5}{l|}{ Table A.4-4 - Morris mean annual Demand $[\mathrm{kWh} . \mathrm{m}-2 . y r-1]$} \\
Loc & HVAC & SPC & EER & & Loc & HVAC & SPC & EER \\
\hline C1 & 35.2 & 48.2 & 1.4 & & C1 & 124.3 & 143.5 & 1.2 \\
C2 & 30.7 & 49.4 & 1.6 & & C2 & 61.0 & 121.1 & 2.0 \\
C3 & 28.0 & 49.7 & 1.8 & & C3 & 46.5 & 103.5 & 2.2 \\
C4 & 36.8 & 47.9 & 1.3 & & C4 & 42.4 & 91.0 & 2.1 \\
C5 & 30.0 & 42.0 & 1.4 & & C5 & 42.2 & 95.1 & 2.3 \\
C6 & 16.8 & 37.6 & 2.2 & & C6 & 26.2 & 69.8 & 2.7 \\
\hline
\end{tabular}

\section{A.5 Convergence Plots}

\section{Annual Total Demand}

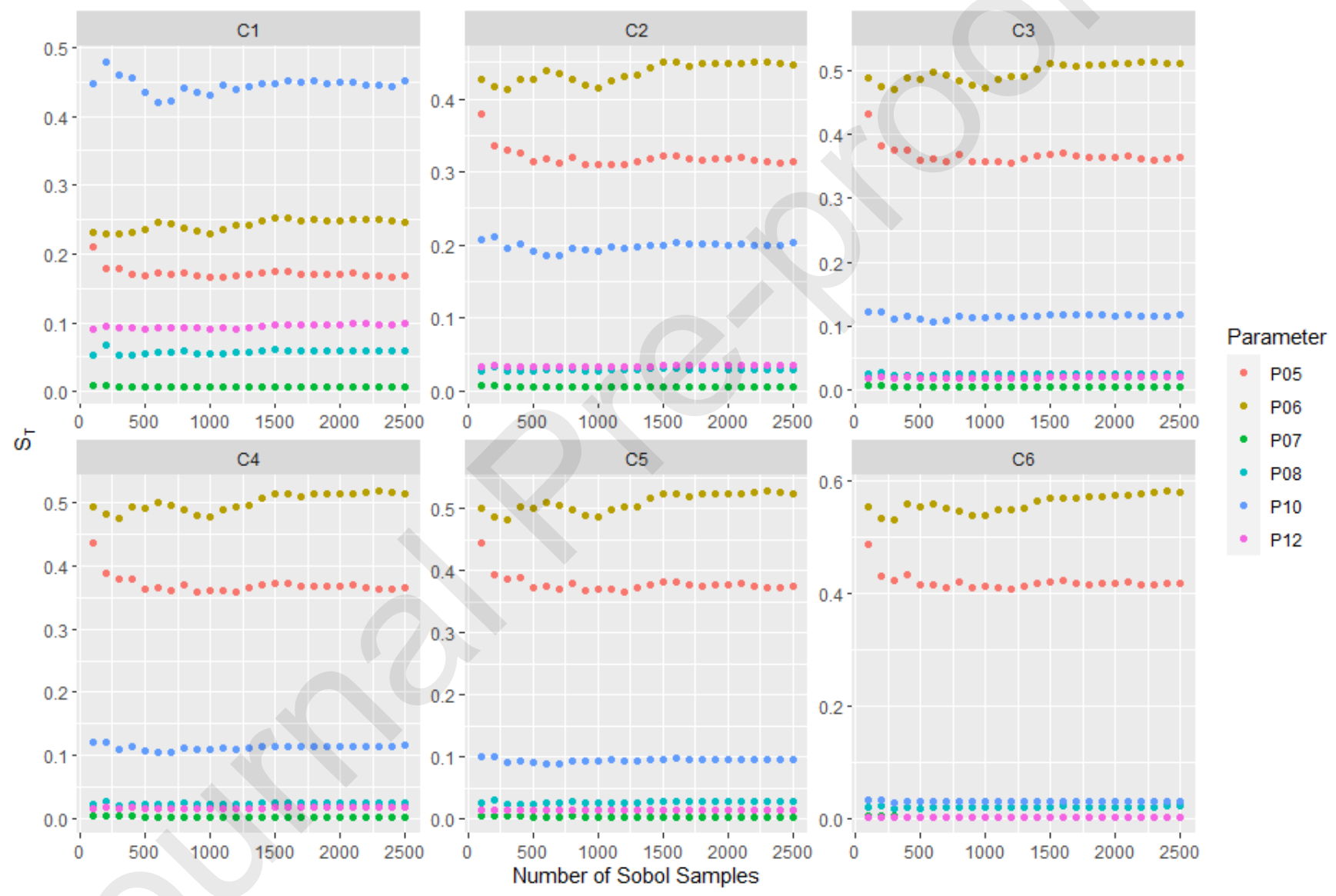

Fig A.5-1 - Convergence Plots for Sobol total indices for total annual electricity demand 


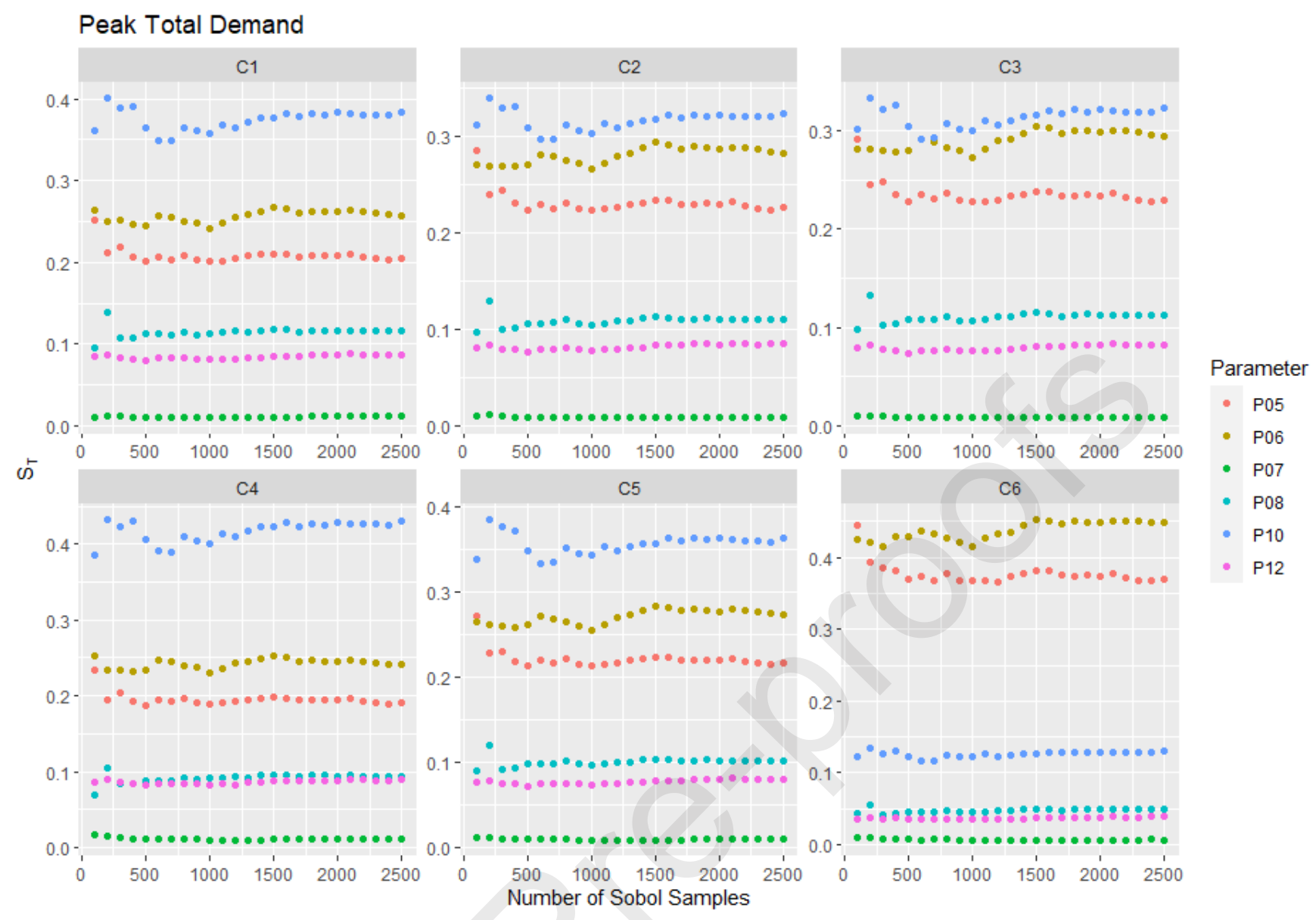

Fig A.5-2 - Convergence Plots for Sobol total indices for total peak electricity demand

\section{Abstract:}

Previous dynamic building simulation studies have not often focused on analysing the sensitivity of peak loads to input parameters. However, these peak loads may have a critical impact on system design capacities and power network operation. This study aims to examine the sensitivity of cooling demand related results (total electricity demand, HVAC end-use and space cooling) in a large office building using two global sensitivity analysis methods: Morris elementary effect and Sobol indices. More specifically, this paper examines the implications of different type of climates to the uncertainty in these different cooling output results and the sensitivity of the different parameters for each result. Moreover, this paper investigates the difference between the effects of annual and peak analysis for cooling demand of office buildings, which can provide insight on cooling demand from the perspectives of total cooling energy and system capacity for building cooling systems, respectively. 
This study has found that generally, the changes are more significant for peak demand than for annual demand. The coefficient of variation for the total peak demand is around $25 \%$ and $21 \%$ for total annual demand. This study identifies that the ventilation rate is the parameter that contributes the largest for the uncertainty in electricity demand of the HVAC end-use, between $50 \%$ to $70 \%$ of the change $\left(\mathrm{S}_{\mathrm{T}}\right)$, both for annual and peak demand. Regarding the effect on total electricity demand, ventilation rate is still one of the most critical factors, but equipment and lighting densities also become a significant contributor to the sensitivity of the total demand.

\section{Highlights:}

- Changes in peak demand are often larger than changes in annual demand.

- Ventilation rate is the parameter with the largest contribution for HVAC demand

- Equipment and lighting density have substantial contributions for total demand

CRediT author statement:

Vasco Zeferina: Conceptualization, Methodology, Software, Formal analysis, Visualisation, Writing - Original Draft, Writing - Review \& Editing; Ruth Wood: Supervision, Writing Review \& Editing; Rodger Edwards: Supervision, Writing - Review \& Editing; Wei Tian: Writing - Review \& Editing

\section{Declaration of interests}

$\bigotimes$ The authors declare that they have no known competing financial interests or personal relationships that could have appeared to influence the work reported in this paper. 
